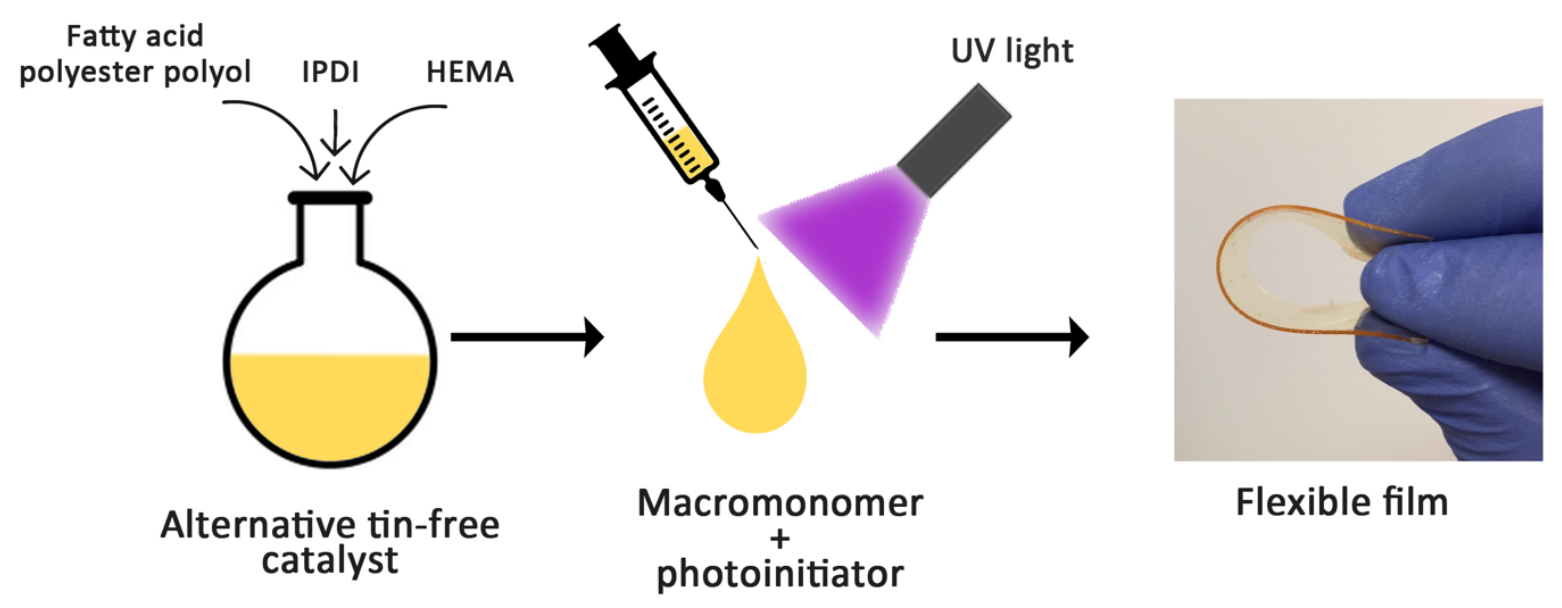

\title{
Fatty-acid-derived ester-urethane macromonomers synthesized using bismuth and zinc catalysts
}

\author{
Malwina J. Niedźwiedź, Gokhan Demirci, Nina Kantor-Malujdy, Peter Sobolewski, \\ Miroslawa El Fray*
}

\begin{abstract}
Department of Polymer and Biomaterials Science, Faculty of Chemical Technology and Engineering, West Pomeranian University of Technology in Szczecin,
\end{abstract}

Al. Piastów 45, 70-311 Szczecin, POLAND

\begin{abstract}
Photocurable materials that can be delivered as liquids and rapidly (within seconds) cured in situ using UV light are gaining increased interest in advanced minimally invasive procedures. The aim of this work was to synthesize and characterize fatty-acid-derived ester-urethane telechelic (methacrylate) macromonomers, suitable for photopolymerization. The commonly used dibutyltin dilaurate catalyst was replaced with bismuth neodecanoate, bismuth tris(2ethylhexanoate), and zinc (II) acetyloacetonate as less-toxic alternative catalysts. Additionally,
\end{abstract}


ethyl acetate was used as a "green" solvent. The progress of the two-step synthesis was monitored with infrared spectroscopy. The chemical structure and molecular weight of the obtained viscous materials was characterized with nuclear magnetic resonance spectroscopy and gel permeation chromatography. Photocrosslinking of the macromonomers into elastomeric films was achieved using $150 \mathrm{~s}$ per spot of UV light $\left(20 \mathrm{~mW} / \mathrm{cm}^{2}\right)$ exposure. Mechanical tensile testing of the films indicated their elasticity up to $120 \%$ and low modulus typical for soft and elastomeric materials. Finally, in vitro cytotoxicity tests showed high cell viability for the case of materials synthesized using bismuth and zinc catalysts. Overall, our results indicate that bismuth and zinc catalysts are excellent alternatives to organotin compounds in the synthesis of photocurable methacrylate ester-urethanes for potential biomedical applications.

\section{Key words:}

bismuth neodecanoate, bismuth tris(2-ethylhexanoate), zinc (II) acetyloacetonate, fatty acid, telechelic macromonomers, methacrylate, urethanes, injectable materials

Corresponding author: mirfray@zut.edu.pl

\section{Introduction}

Advances in diagnostic imaging, as well as surgical technique and instrumentation have synergistically enabled rapid growth of minimally invasive procedures. ${ }^{1}$ These procedures have advantages over traditional surgical techniques, such as shortening the treatment time and reducing the risk of complications. These surgical approaches motivate further research into wide range of injectable materials ${ }^{2,3}$ that can enable tissue repair, drug delivery, cell therapy, sensing, imaging, etc. Of particular interest are materials that can be injected as a liquid and then crosslinked in situ, ${ }^{4}$ under different stimuli, such as light, temperature, or $\mathrm{pH}$. While 
hydrogel based materials have been most popular, curable elastomeric materials can be well suited for specific tasks, such as heart muscle repair after infarct or hernia repair. ${ }^{5,6}$

Towards this aim, we have previously developed injectable and photocurable ester-urethane macromonomers based on fatty acid derivatives obtained from vegetable oils. ${ }^{7}$ Polyurethanes are already widely used in medical and pharmaceutical applications due to their favorable safety profiles and mechanical properties, as well as potential for biodegradability. ${ }^{8}$ In the case of our injectable macromonomers, once photocured, the obtained elastomeric materials exhibit similar mechanical properties to human soft tissue (i.e. abdominal wall), along with slow enzymatic and hydrolytic degradation. ${ }^{9}$ Overall, these materials displayed low toxicity and similar immune response to polylactic acid in a rabbit model, making them promising for minimally invasive surgical procedures. ${ }^{6}$

However, in our previous work the ester-urethane macromonomers were synthesized with use of organotin-based catalyst, dibutyltin dilaurate (DBTDL). ${ }^{7}$ Overall, tin-based catalysts are commonly used for the synthesis of polyesters and polyurethanes as elastomers and coatings. They act as Lewis acids ${ }^{10}$ and possess high catalytic activity. ${ }^{11}$ However, tin-based compounds and organotin compounds, such as DBTDL in particular, exhibit cytotoxicity, ${ }^{12}$ are difficult to remove from polymers, and have adverse environmental effects. ${ }^{13}$ Therefore, their usage in medical applications is limited ${ }^{14}$ and there is growing interest in "greener" organotin-free reaction pathways. ${ }^{15}$

Towards this aim, alternative catalytic systems are being explored that replace tin with other metals, such as zinc, titanium, zirconium, manganese, etc. ${ }^{16-21}$ Metal catalysts based on bismuth $^{22,23}$ and zinc $^{24}$ are of particular interest, due to their role in the human metabolism and use in pharmaceuticals, cosmetics, etc. Recently, they were tested in the synthesis of biodegradable polyesters, such as poly( $\varepsilon$-caprolactone) or poly(lactide) ${ }^{25}$ Overall, the activity of zinc and bismuth catalysts was similar, but lower than that of the organotin catalyst DBTDL. 
The aim of this work was to test two bismuth and one zinc-based catalysts as possible alternatives to organotin compounds for the synthesis of injectable and photocurable esterurethane macromonomers with telechelic methacrylic groups. Additionally, we also switched to a "green" solvent, ethyl acetate (EtOAc), ${ }^{26}$ instead of dichloromethane (DCM) used in our previous study. We examined the effect of catalyst concentration on the reaction kinetics and chemical structure of the synthesized macromonomers, as well as on the physico-chemical properties and cytotoxicity of final photocured elastomeric materials.

\section{Experimental Section}

\subsection{Materials}

Dimer-linoleic-acid-based polyester polyol (Priplast 1838) was kindly provided by Croda (The Netherlands), ${ }^{1} \mathrm{H}$ NMR spectra with peak assignment can be find in SI Fig S1. Isophorone diisocyanate (98\%) (IPDI) and 2-hydroxyethylmethacrylate (97\%) (HEMA) were purchased from Merck KGaA (Germany). Dibutyltin dilaurate (DBTDL), bismuth neodecanoate (BiNDE), zinc (II) acetyloacetonate (ZnAc), and phenotiazine (PTZ) were purchased from Sigma Aldrich (Poznań, Poland). Bismuth tris(2-ethylhexanoate) (BiHex) was purchased from Alfa Aesar (Germany). Photoinititor Omnirad 819 was purchased from IGM resins (Netherlands). Ethyl acetate (EtOAc) and ethanol were purchased from Chempur (Poland). HEMA was used after distillation under reduced pressure; all other reagents were used as received. Murine fibroblast cell line, L929, as well as all cell culture reagents were purchased from Sigma Aldrich (Poznań, Poland).

\subsection{Synthesis of telechelic ester-urethane macromonomers}

The synthesis of telechelic macromonomers was performed in two steps (Figure 1) based on our previous work, ${ }^{7}$ but with two primary modifications: 1) the reaction temperature was increased from $35^{\circ} \mathrm{C}$ to $70{ }^{\circ} \mathrm{C}$ and 2) EtOAc was used instead of dichloromethane (DCM). 


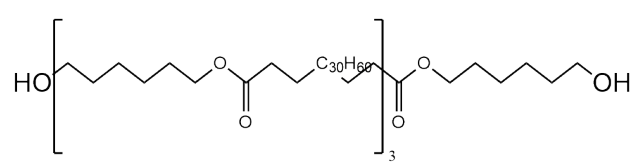

PRIPLAST-1838
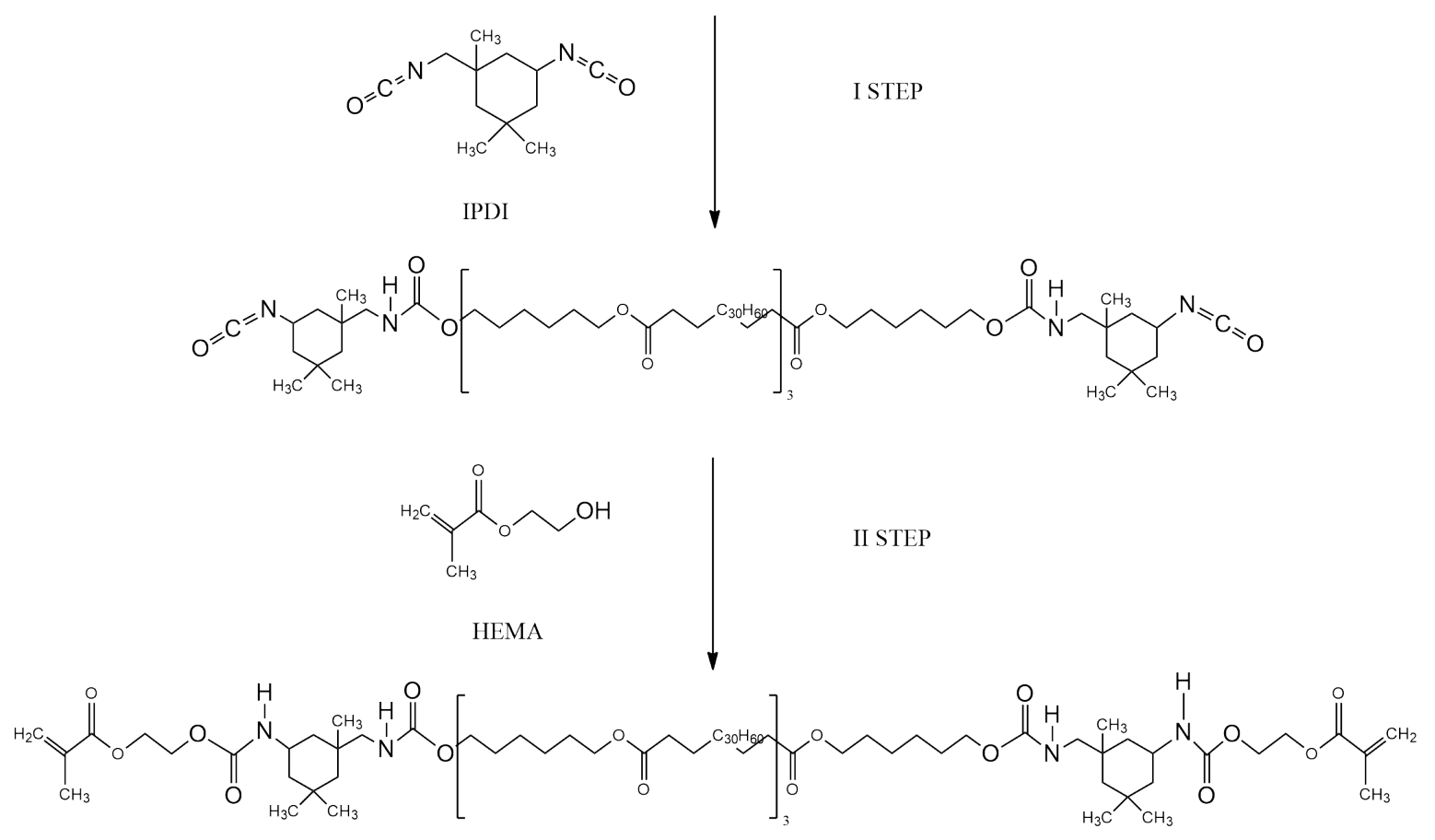

Figure 1 Scheme of the synthesis of telechelic macromonomer containing ester and urethane groups

In the first step, $25 \mathrm{ml}$ of EtOAc was introduced into a $250 \mathrm{ml}$ round-bottom flask and degassed with three argon/pump cycles. Next, an appropriate amount of catalyst (2 or 4 mol\% calculated relative to amount of polyester polyol $)$ and $6.5 \mathrm{ml}(0.052 \mathrm{mmol})$ of IPDI were added into the flask that was placed in an ice bath. At the same time, $25 \mathrm{~g}(0.013 \mathrm{mmol})$ of polyester polyol was dissolved in $25 \mathrm{ml}$ of EtOAc. Next, the dissolved polyol was added dropwise into the ice-cold mixture. When the addition was completed, the flask was transferred to an oil bath and the reaction was continued at $70{ }^{\circ} \mathrm{C}$. Progress of the reaction was monitored by tracking the ratio between FT-IR absorbance at $2262 \mathrm{~cm}^{-1}$, which corresponds to $\mathrm{N}=\mathrm{C}=\mathrm{O}$ vibration in isocyanate groups of IPDI, and at $1526 \mathrm{~cm}^{-1}$, which corresponds to $\mathrm{N}-\mathrm{H}$ bending vibrations of the formed urethane bonds. The first step was considered completed when the ratio stabilized, typically at values between 3 and 5 . 
In the second step, $6 \mathrm{mg}(0.03 \mathrm{mmol})$ of phenothiazine, a second aliquot of a catalyst (the same mol\% as in first step), and $6.6 \mathrm{ml}(0.054 \mathrm{mmol})$ of 2-hydroxyethyl methacrylate (HEMA) were introduced, while protecting the reaction from the light. After all of the isocyanate groups were converted, as determined by FT-IR by the absence of the band at $2262 \mathrm{~cm}^{-1}$, the flask was removed from the oil bath and cooled down to room temperature. The product was then precipitated into four-fold excess of ice-cold methanol three times and any residual solvent was evaporated under reduced pressure at $50{ }^{\circ} \mathrm{C}$. The obtained product was a transparent, highly viscous, sticky, yellowish liquid. The same procedure was repeated for all catalysts, for both 2 and 4 mol\% concentrations. The series of macromonomers synthesized with different catalysts are abbreviated as follows: PrDBTDL, PrBiNDE, PrBiHex, PrZnAc.

\subsection{Photocuring process}

Crosslinked films were prepared according to the following procedure: photoinitiator $2 \% \mathrm{w} / \mathrm{w}$ (Omnirad 819) was mixed with macromonomer ( 20 g) dissolved in $25 \mathrm{ml}$ EtOAc. Residual solvent was evaporated under reduced pressure after a homogenous mixture was obtained. Then, 1-mm-thick films were produced by pouring the final composition onto glass plate and spreading with a steel applicator. The composition was then irradiated with a DYMAX Bluewave LED Prime UVA (USA) light source, with a narrow spectral range and maximum intensity at a wavelength $\lambda_{\max }$ of $385 \mathrm{~nm}$. The intensity of the radiation was adjusted to 20 $\mathrm{mW} / \mathrm{cm}^{2}$ with the help of radiometer, AktiPrint (Technigraf $\mathrm{GmbH}$ ). Photocrosslinking was carried out in air atmosphere, as well as under argon, in a glove box. The exposure time was 150 seconds for each spot $\left(2.25 \mathrm{~cm}^{2}\right)$ and was carried out stepwise across the entire plate (10 cm x $20 \mathrm{~cm})$.

\subsection{Characterization methods}


Fourier transform infrared spectroscopy (FTIR) was performed by using BRUKER ALPHA Platinum apparatus (Germany) at room temperature in the range of $4000-600 \mathrm{~cm}^{-1}$, at a resolution of $2 \mathrm{~cm}^{-1}$ and using 32 scans. Liquid (viscous) macromonomers were analyzed in transmission mode, after pouring samples between $\mathrm{NaCl}$ plates. Spectra of films after photocrosslinking were obtained using reflection mode and the ATR snap-in with diamond crystal. Spectra were analyzed using EZ OMNIC software.

Nuclear magnetic resonance (NMR) spectra of all obtained macromonomers were recorded using Bruker DPX HD-400 MHz. The instrument was equipped with a $5 \mathrm{~mm} \mathrm{Z}$-gradient broadband decoupling inverse probe. All experiments were conducted at $25^{\circ} \mathrm{C}$. Samples for NMR were prepared by dissolving approx. $20 \mathrm{mg}$ of macromonomer in $0.7 \mathrm{ml}$ of $\mathrm{CDCl}_{3}-d$.

Gel permeation chromatography (GPC) was used to determine the final molecular weights and molecular weight distributions of synthesized macromonomers. GPC measurements were performed using a Wyatt (Germany) instrument equipped with a guard column and four Perfect Separation Solutions (PSS) columns (50, 100, 1000 and 100000 Å), a WGE Dr. Bures Dn 2010 differential refractometer (RI), and Wyatt MALLS DAWN HELEOS multi-angle light scattering (LS) detectors. The measurements were performed in THF as eluent at $35^{\circ} \mathrm{C}$ at a flow rate of $1 \mathrm{~mL} / \mathrm{min}$. An average molar (apparent) mass $\left(\mathrm{M}_{\mathrm{n}}, \mathrm{M}_{\mathrm{w}}, \mathrm{M}_{\mathrm{z}}\right)$ and dispersity index, $Ð\left(M_{w} / M_{n}\right)$ were determined by gel chromatography using calibration with 8 different linear polystyrene standards (molecular weight of 970, 1990, 5030, 10680, 19760, 34800, 70950 and $126700 \mathrm{~g} / \mathrm{mol}$ (Polymer Laboratories and Solutions LLC, USA)). Measurements were made in THF at $35^{\circ} \mathrm{C}$. The sample solutions were filtered using a $0.20 \mu \mathrm{m} \mathrm{SRP} 20$ filter prior to injection onto the column. PSS WinGPC Unity software was used for data storage and calculations.

In order to assess the gel fraction, the cross-linked samples were weighted ( $\left.\mathrm{W}_{\text {initial }}\right)$ and then refluxed for 6 hours in Soxhlet apparatus (Behr Labor-Technik, Germany) in EtOAc, which was found to be a suitable solvent for the macromonomers. The samples were dried under 
reduced pressure until a constant mass $\left(\mathrm{W}_{\text {final }}\right)$ was achieved. The gel fraction was calculated according to following equation (Equation 1):

$$
\text { Gel fraction }(\%)=\frac{W_{\text {final }}}{W_{\text {initial }}} * 100
$$

Dynamic viscosity tests of macromers were carried out using a BROOKFIELD AMETEK rotary rheometer (USA) with the following parameters: measuring head in the plate-plate system with a diameter of $\phi=40 \mathrm{~mm}$, distance between plates $\mathrm{h}=1 \mathrm{~mm}$, deformation of $30 \%$, constant shear rate $\dot{\gamma}(1 / \mathrm{s}): 0.200$, and at a temperature of $25^{\circ} \mathrm{C}$.

The mechanical tensile properties of photocured samples were assessed using an Instron 3366 (UK) testing system with a $500 \mathrm{~N}$ load cell, at crosshead speed of $25 \mathrm{~mm} / \mathrm{min}$. The crosshead speed was selected from the range of $10-50 \mathrm{~mm} / \mathrm{min}$, as typical for tensile testing of soft connective tissue. ${ }^{27}$ The samples were of rectangular: $10 \mathrm{~mm}$ in width, $60 \mathrm{~mm}$ in length, and $0.5 \mathrm{~mm}$ thick. The following parameters were determined: tensile strength $\left(\sigma_{\mathrm{br}}\right)$, elongation at break $\left(\varepsilon_{\mathrm{br}}\right)$, and modulus of elasticity (E). The modulus was calculated at 2\%-3\% and 5\%-6\% elongation, respectively.

Cytotoxicity of materials was tested via extract tests according to ISO10993-5 28 in similar fashion to our previous works. ${ }^{29,30}$ Briefly, strips of photocured materials (area: $3 \mathrm{~cm}^{2}$, thickness: $0.5 \mathrm{~mm}$ ) were cut into smaller pieces, placed in a well of a 24-well plate, and incubated in $1 \mathrm{ml}$ of complete growth medium (Dulbecco's Modified Eagle Medium (DMEM), containing 10\% Fetal Bovine Serum (FBS), $2 \mathrm{mM}$ L-glutamine, $100 \mathrm{U} / \mathrm{mL}$ penicillin and $100 \mu \mathrm{g} / \mathrm{mL}$ streptomycin for 24 hours in a $\mathrm{CO}_{2}$ incubator for cell culture at $37^{\circ} \mathrm{C}$. The following controls were used: 1) negative control: commercial, non-toxic poly( $\varepsilon$-caprolactone) (PCL, Capa ${ }^{\mathrm{TM}}$ 6430), 2) positive (toxic) control: nitrile glove (Mercator Nitrylex Classic, Kraków, Poland), 3) sham: media in an empty well. In parallel, $10 \times 10^{3}$ L929 cells (passage 10-25) were plated per well in a 96-well plate in complete growth medium. After incubation for 24 hours in a $\mathrm{CO}_{2}$ 
incubator for cell culture at $37^{\circ} \mathrm{C}$, the medium in the plate with cells was aspirated and replaced with $100 \mu \mathrm{L}$ of extract medium from a given sample (5-6 technical replicates, 2 samples per material). The plates were then returned to the cell culture incubator for another 24 hours of culture. Cell viability was then assessed using light microscopy (Delta Optical IB-100, Mińsk Mazowiecki, Poland) and the resazurin viability assay.$^{31}$ Briefly, $20 \mu \mathrm{l}$ of resazurin stock $(0.15$ $\mathrm{mg} / \mathrm{mL}$ in phosphate-buffered saline) was added to each well (as well as to blank wells with media but no cells) and then incubated for 4 hours in the cell culture incubator at $37{ }^{\circ} \mathrm{C}$. Fluorescence signal was then measured using a multi-functional plate reader (Biotek Synergy HTX, Winooski, VT, USA): excitation $540 \mathrm{~nm}$, emission $590 \mathrm{~nm}$. Fluorescence intensity (arbitrary units) of the blank was subtracted from all measured samples/controls and cell viability was expressed as percent of sham-extract treated cells.

\section{Results and Discussion}

\subsection{Progress of the reaction based on infrared spectroscopy}

Proper choice of non-toxic catalysts is the key to successful synthesis of polymers for biomedical applications. Here, we assessed the potential of two bismuth derivatives (BiNDE and $\mathrm{BiHex}$ ) and a zinc (ZnAc) compound as alternatives to the organotin catalyst, DBTDL for the synthesis of photocurable macromonomers via two-step reaction (see scheme in Figure 1). The chemical structures of all four catalysts are presented in Figure 2.

a)

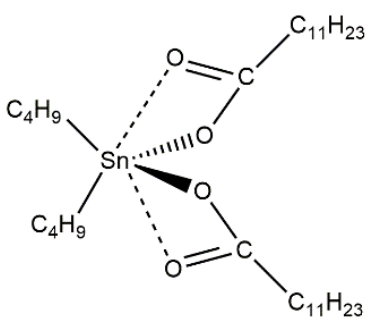

c) b)

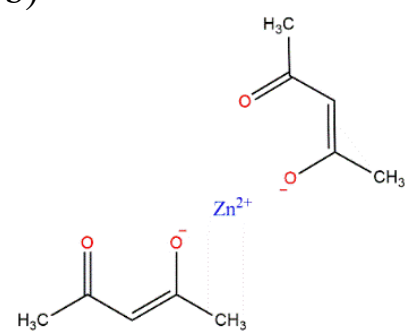

d) 

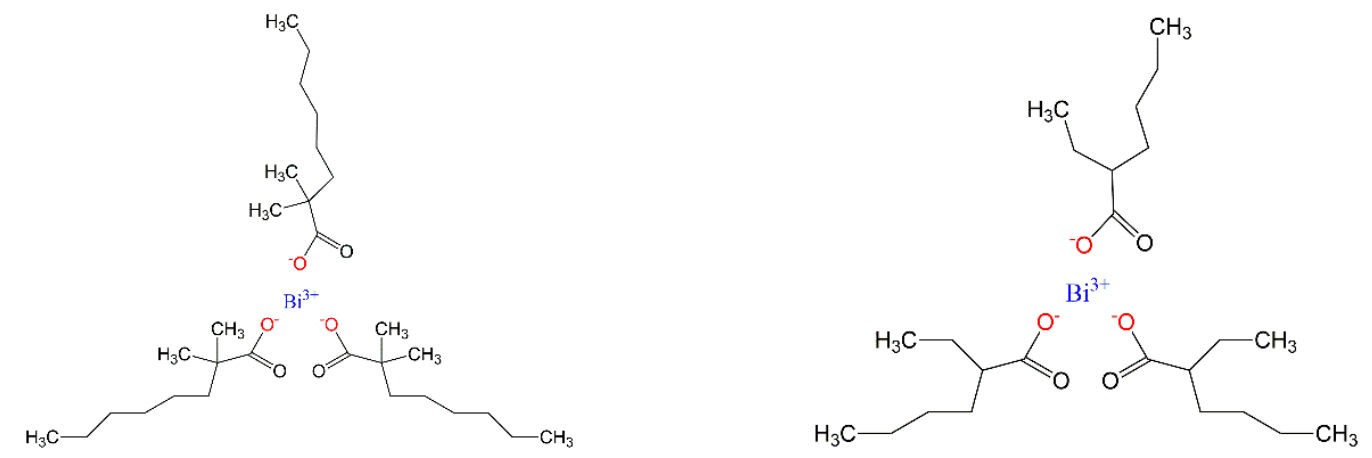

Figure 2 Chemical structures of catalysts used in the study: (a) DBTDL, (b) ZnAc, (c) BiNDE, and (d) BiHex.

Overall, the reaction progress for all of the tested catalysts was similar. As a representative example, the FT-IR spectra used to monitor the progress of the synthesis with the use of BiHex 2 mol\% are presented in Figure 3 (the data for the other catalysts are available in the SI, see Figures S2-S8). The kinetics of all the reactions (ratio of $\mathrm{A}_{2262}$ to $\mathrm{A}_{1526}$ as a function of time) are presented in Figure 4. A summary of the reaction conditions, times, and yields are presented in Table 1.

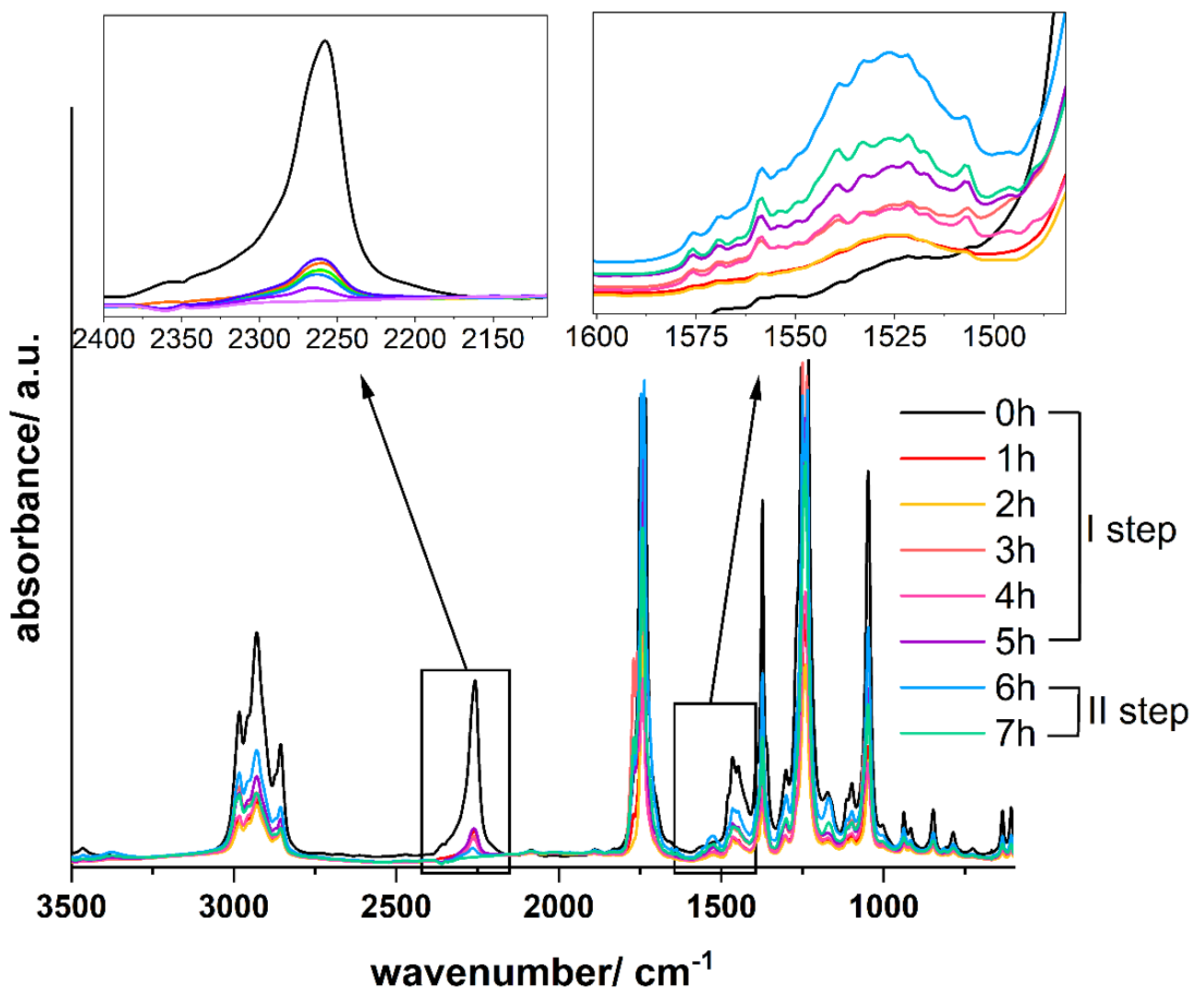

Figure 3 FT-IR spectra used to monitor the progress of the reaction with the use of 2 mol\% BiHex 

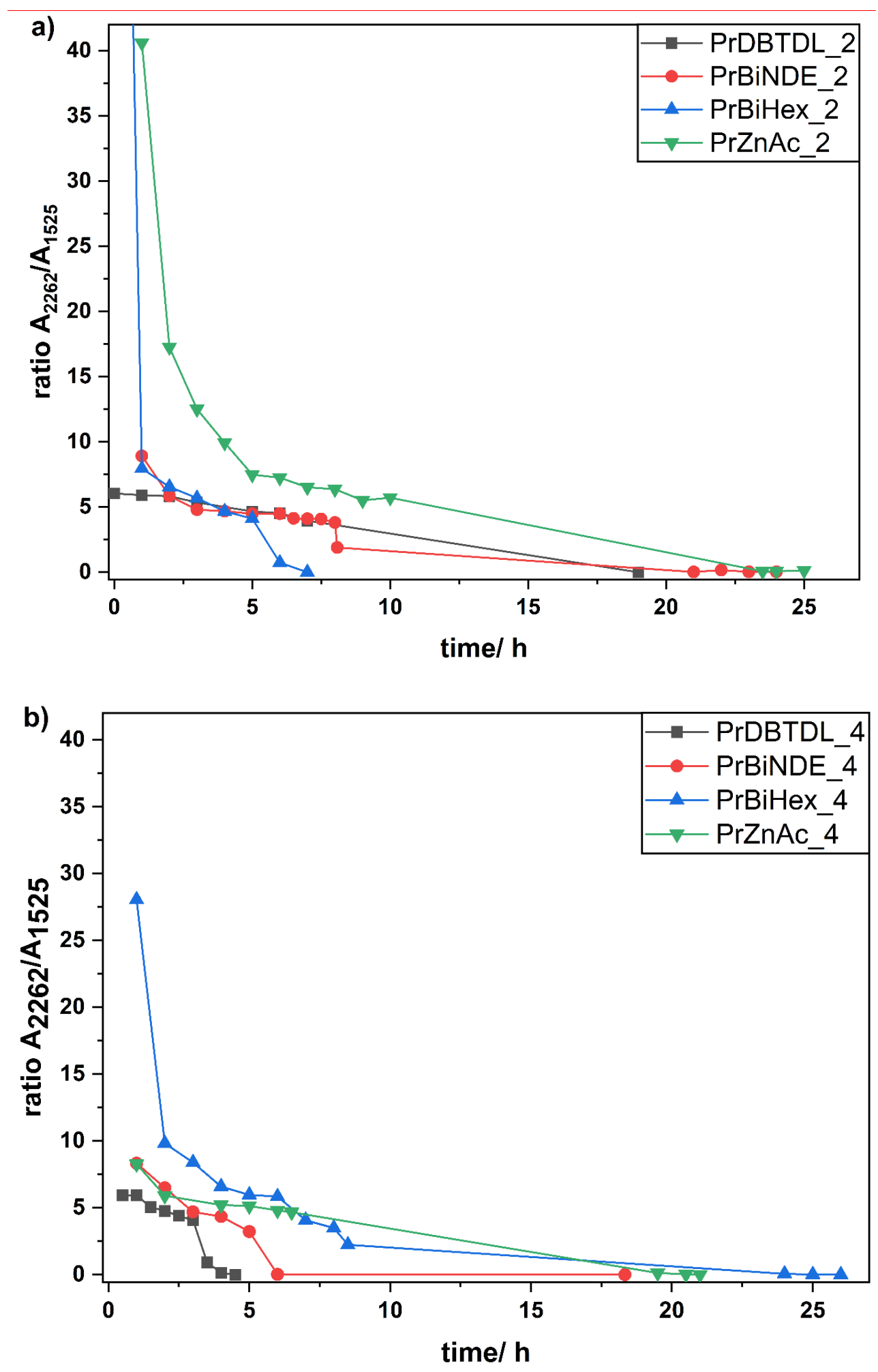

Figure 4 The progress of reactions according to the change in the absorbance ratio of $A_{2262}$ to $A_{1526}$. a) Synthesis carried out with 2 mol\% of catalyst per step. b) Synthesis carried out with 4 mol\% of catalyst per step. 
Table 1 Summary of the reaction parameters

\begin{tabular}{|c|c|c|c|c|c|c|}
\hline Materials & $\begin{array}{c}\text { Concentration } \\
\text { (per step) } \\
{[\mathrm{mol} \%]}\end{array}$ & $\begin{array}{c}\text { I step } \\
\text { [hours] }\end{array}$ & $\begin{array}{c}\mathrm{A}_{2262} / \mathrm{A}_{1525} \\
\text { after I step }\end{array}$ & $\begin{array}{c}\text { II Step } \\
\text { [hours] }\end{array}$ & $\begin{array}{c}\text { Total } \\
{[\text { hours] }}\end{array}$ & $\begin{array}{c}\text { Reaction } \\
\text { Yield } \\
{[\%]}\end{array}$ \\
\hline PrDBTDL_2 & 2 & 7.0 & 3.96 & 12.0 & 19.0 & 66 \\
\hline PrBiNDE_2 & 2 & 8.0 & 3.81 & 17.0 & 25.0 & 64 \\
\hline PrBiHex_2 & 2 & 5.0 & 4.11 & 2.0 & 7.0 & 65 \\
\hline PrZnAc_2 & 2 & 10.0 & 5.72 & 15.0 & 25.0 & 62 \\
\hline PrDBTDL_4 & 4 & 3.0 & 4.07 & 1.5 & 4.5 & 68 \\
\hline PrBiNDE_4 & 4 & 5.0 & 3.22 & 13.3 & 18.3 & 66 \\
\hline PrBiHex_4 & 4 & 8.0 & 3.49 & 18.0 & 26.0 & 70 \\
\hline PrZnAc_4 & 4 & 6.5 & 4.67 & 14.5 & 21.0 & 68 \\
\hline
\end{tabular}

As can be seen from Table 1, the reaction yields for all of the performed reactions were similar, ranging from 62 to $70 \%$. All of the current reactions took less time, as compared to the total reaction time in our previous study (approx. 72 hours) where DCM was used as the solvent during the reaction..$^{6,7}$ Further, clear differences between catalysts and concentrations were observed in the reaction times. In the case of using $2 \mathrm{~mol} \%$ of the catalyst, it was observed that BiHex was the fastest, with a total reaction time of 7 hours, while the reactions with the other catalysts were similar - and considerably longer (19-25 hours).

When the catalyst amount per step was doubled to $4 \mathrm{~mol} \%$, the reaction times were reduced, as anticipated, for all catalysts, except BiHex. The increase in catalyst concentration had a particularly marked effect in the case of DBTDL, reducing the duration of II step to 1.5 hours and the total reaction time from 19 to 4.5 hours. Meanwhile, for both BiNDE and ZnAc the change in reaction time was modest ( $<10$ hours), with total reaction times of approx. 20 hours. These differences in the concentration dependence may be explained by differences in the catalytic mechanism between DBTDL and the remaining non-organotin catalysts (see Figure $5)$. 
a)<smiles>[R]N=C=O</smiles><smiles></smiles><smiles>[R]NC(=O)CF</smiles>

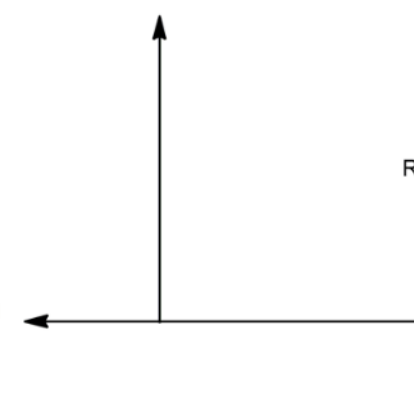

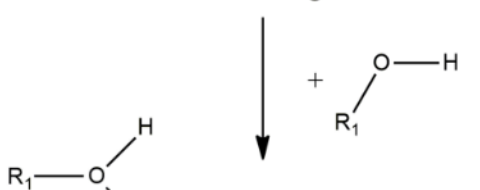

b)

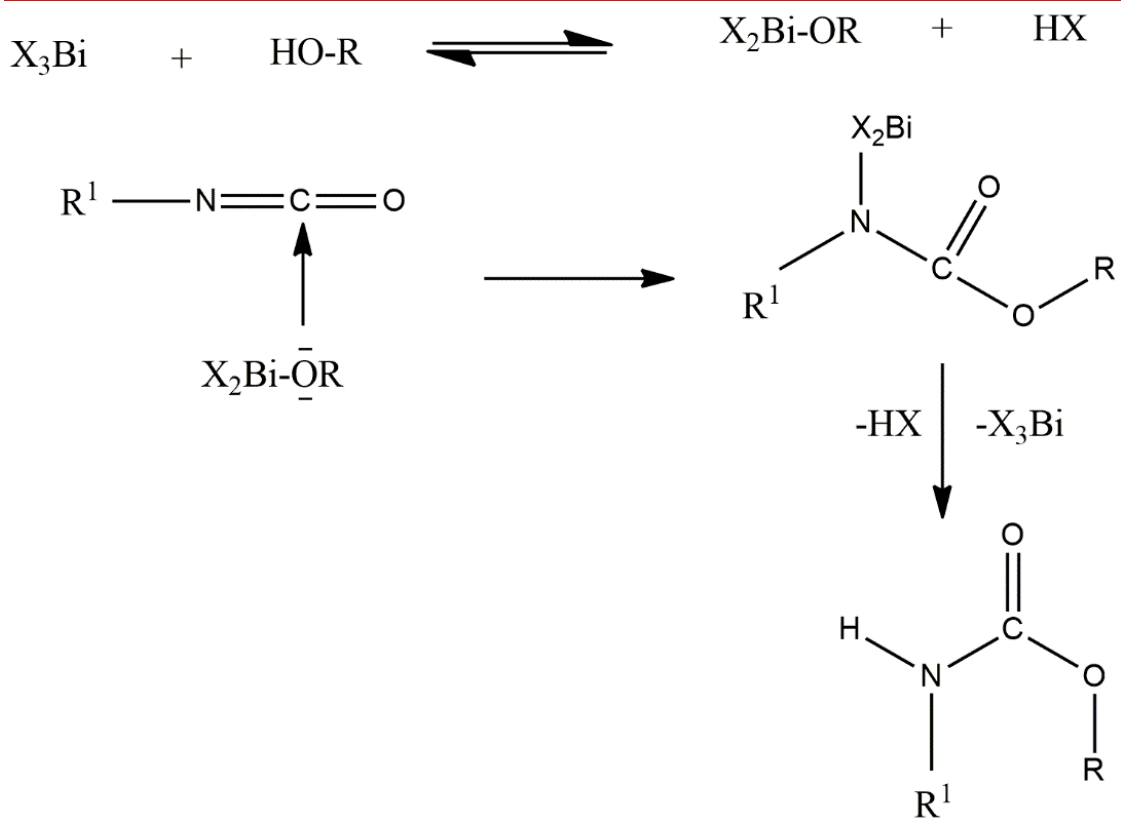

Figure 5 Catalytic mechanisms of polyurethane synthesis for a) organotin-based catalysts and b) bismuth-based catalysts

DBTDL catalyst acts as a Lewis acid that can interact with $\mathrm{N}=\mathrm{C}=\mathrm{O}$ groups - in this case coming from IPDI - and increase their electrophilicity (Figure 5a). Further, DBTDL is a Lewis acid with pKa 11 and therefore this catalyst can be expected to be more active at higher concentrations, resulting in reduced reaction times. In contrast, according to literature, ${ }^{11,32}$ the catalytic activity of both of the bismuth catalysts and the zinc one is based on an insertion 
mechanism (Figure 5b). In this case, the catalysts exchange their ligands with the alcohol-in this case the polyester polyol-or interact with hydrogen from the $-\mathrm{OH}$ in alcohol (here the polyester polyol). Therefore, steric effects may have a major effect on the reaction time. This can then account for the differences between BiHex and BiNDE; while both catalysts have 3 ligands, BiHex is less bulky ( 8 vs 10 carbons), explaining the faster reaction rate. The increase in total reaction time (from 7 to 26 hours) observed after increasing the concentration of BiHex catalyst to $4 \mathrm{~mol} \%$. Longer reaction time in II step for PrBiHex at 4 mol\% can result from side reaction manifested by formation of allophanate crosslinks. The effect of formed allophanate crosslinks during the second step effected an increased reaction time. BiHex is used an allophanatization catalyst for polyurethane formation within the referred patent ${ }^{33}$. Additionally, allophanatization reactions are reversible and dissociation of the obtained allophanates occurs quickly ${ }^{34}$, therefore, we did not observe allophanates in the final structure (confirmed by ${ }^{1} \mathrm{H}-$ and ${ }^{13} \mathrm{C}-\mathrm{NMR}$ spectroscopy, see in Figure $\left.7 \mathrm{a}-\mathrm{b}\right)$.

\subsection{Chemical structure of macromonomers by IR spectroscopy}

The FT-IR measurements also permitted us to confirm that the chemical structures of the obtained macromonomers were consistent with the assumed reaction mechanism and with our previous work where DBTDL was used as catalytic system. ${ }^{7}$ Overall, all of the obtained spectra were similar, indicating that the macromonomers obtained using the new catalysts had the same chemical structures. A representative FT-IR spectrum of PrBiHex_2 macromonomer, as compared to the starting material, polyester polyol Priplast-1838, is presented in Figure 6. Spectra for the other macromonomers are available in the SI, see Figure S9 and S10. The absorbance bands at 3368 and $1525 \mathrm{~cm}^{-1}$ correspond to stretching vibrations of $\mathrm{N}-\mathrm{H}$ in urethane groups. The band at $1643 \mathrm{~cm}^{-1}$ corresponds to stretching vibrations of $\mathrm{C}=\mathrm{C}$ from the coupling of HEMA. Meanwhile, the bands 2921 and $2853 \mathrm{~cm}^{-1}$ correspond to stretching vibrations of C- 
$\mathrm{H}$ in $-\mathrm{CH}_{2}$ and $-\mathrm{CH}_{3}$. The band at approx. $1732 \mathrm{~cm}^{-1}$ is characteristic for stretching of $\mathrm{C}=\mathrm{O}$ in ester bonds of the polyester polyol. The band at $1460 \mathrm{~cm}^{-1}$ corresponds to $\mathrm{R}^{-} \mathrm{CH}_{2}-\mathrm{CH}_{3}$ and $-\mathrm{C}-$ $\mathrm{C}$ - in rings, while the band at $1369 \mathrm{~cm}^{-1}$ corresponds to rocking vibrations of $\mathrm{C}-\mathrm{H}$ in fatty acid chains of polyester polyol. The bands at 1302 and $1049 \mathrm{~cm}^{-1}$ correspond to RCOOR' in esters, while the bands at $1236 \mathrm{~cm}^{-1}$ and $1168 \mathrm{~cm}^{-1}$ correspond to $-\mathrm{C}-\mathrm{O}-$ stretching vibrations and $-\mathrm{C}$ $\mathrm{O}-\mathrm{C}(=\mathrm{O})$ stretching vibration, respectively.

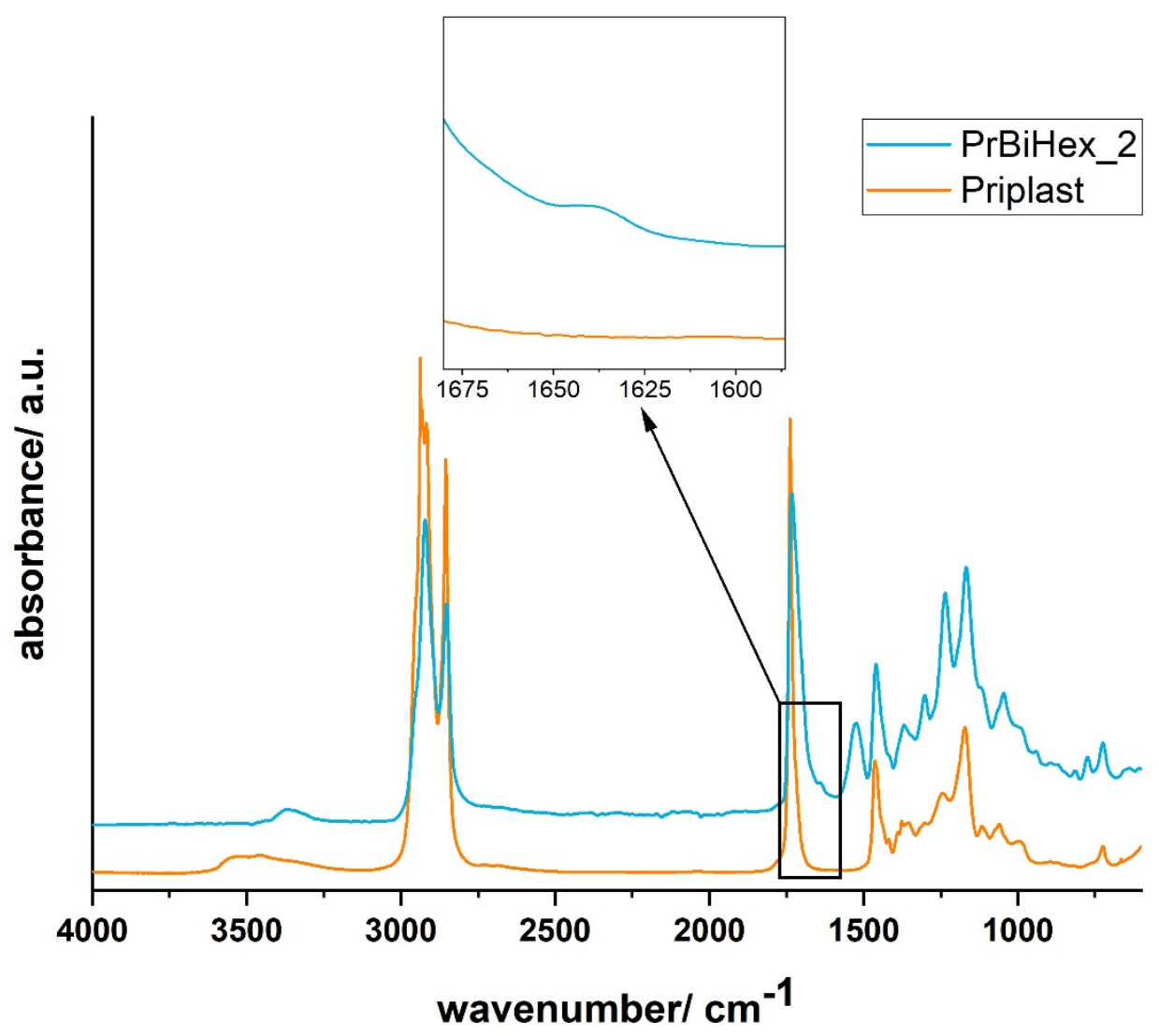

Figure 6 FT-IR spectra of macromonomer obtained with 2 mol\% BiHex

\subsection{Chemical structure of macromonomers by NMR spectroscopy}

The chemical structure of the obtained macromonomers was also confirmed by ${ }^{1} \mathrm{H}-\mathrm{NMR}$ and ${ }^{13} \mathrm{C}$-NMR spectroscopy. The analysis of NMR spectra also confirmed that all of the obtained macromonomers had similar structures, consistent with our expectations based on our prior 
work. ${ }^{7}$ As a representative example, Figure 7 presents ${ }^{1} \mathrm{H}-$ and ${ }^{13} \mathrm{C}-\mathrm{NMR}$ spectra of macromonomer obtained using BiHex at 2 mol\% per step (PrBiHex_2). The remaining ${ }^{1} \mathrm{H}-$ NMR spectra for the materials synthesized with other catalysts are included in the SI (see Figure S11 and S12).

a)

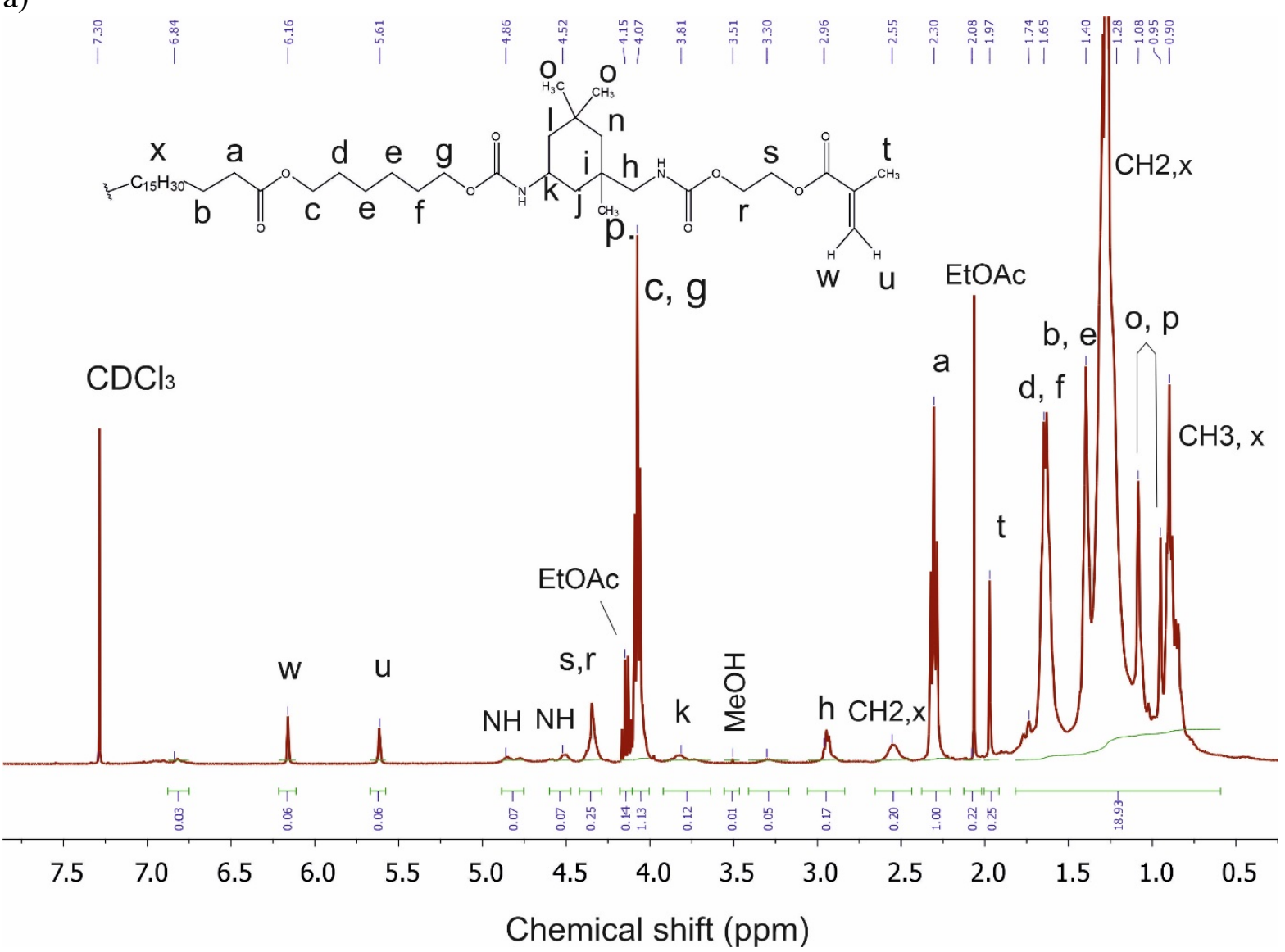




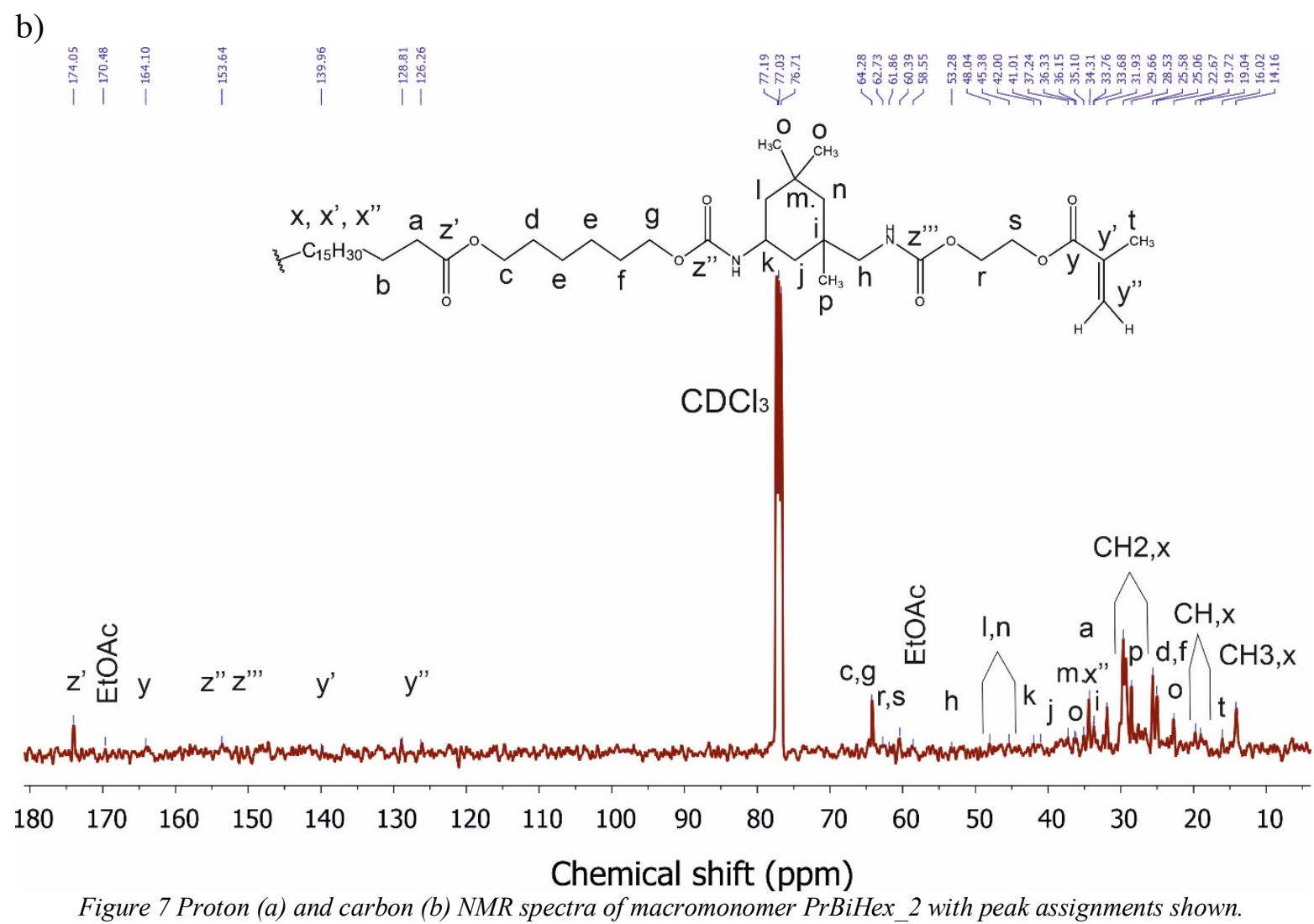

In the ${ }^{1} \mathrm{H}-\mathrm{NMR}$ spectrum, peaks at 4.52 and $4.86 \mathrm{ppm}$ confirm the presence of the $\mathrm{N}-\mathrm{H}$ groups of the urethane bonds, whereas peaks at 5.61 and $6.16 \mathrm{ppm}$ confirm the presence of $\mathrm{C}=\mathrm{C}$ groups from the attachment of HEMA. Meanwhile, in the ${ }^{13} \mathrm{C}$-NMR spectrum, the most important peaks are at 129 and $141 \mathrm{ppm}$, because they correspond to $\mathrm{C}=\mathrm{C}$ double bonds of the attached HEMA.

\subsection{Molecular mass and viscosity of macromonomers}

The results of GPC analysis are presented in Figure 8 and Table S1 in the SI. For all of the macromonomers, an increase of molecular mass and decrease of dispersion was observed, as compared to the starting polyester polyol, Priplast 1838 . For reactions conducted with 2 mol\% of catalyst per step, the highest $\mathrm{M}_{\mathrm{w}}(\sim 13000 \mathrm{~g} / \mathrm{mol})$ was obtained with BiHex as catalyst. Meanwhile, for the case of reactions with 4 mol\% of catalyst per step, the highest $\mathrm{M}_{\mathrm{w}}$, also approx. $13000 \mathrm{~g} / \mathrm{mol}$, was obtained with use of $\mathrm{ZnAc}$. The $Đ$ of all obtained macromonomers was similar, approx. 1.75. Likewise, for all macromonomers, the shapes of the chromatograms 
are similar, with only small shifts observed. Importantly, the obtained macromonomers do not differ significantly in $\mathbf{M}_{\mathrm{w}}$ from those obtained in our previous work, ${ }^{7}$ despite the changes in reaction conditions (catalysts and solvent).

a)

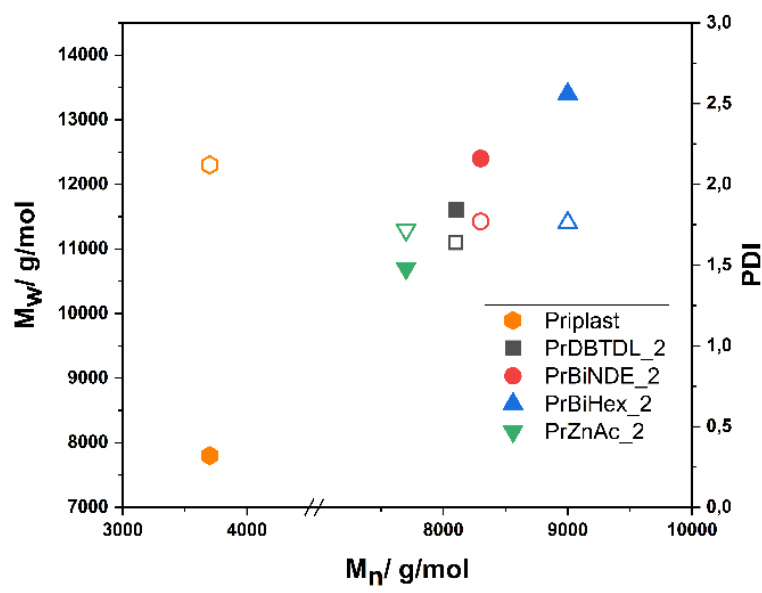

c)

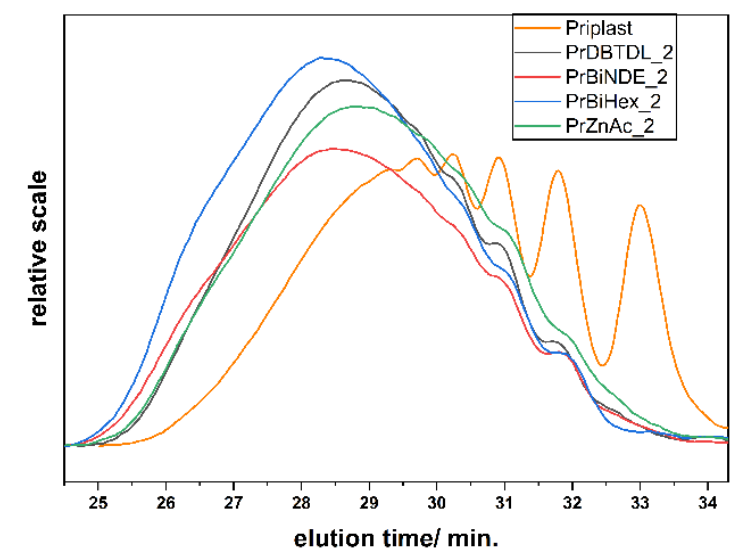

b)

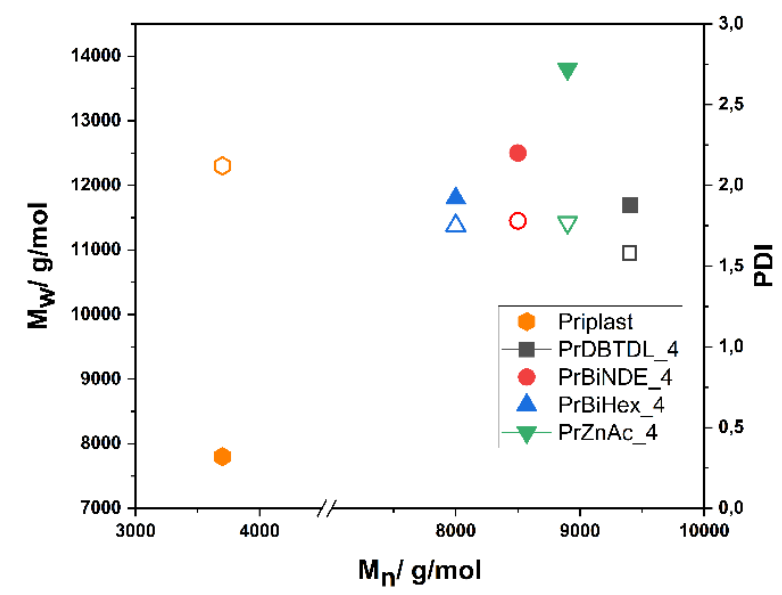

d)

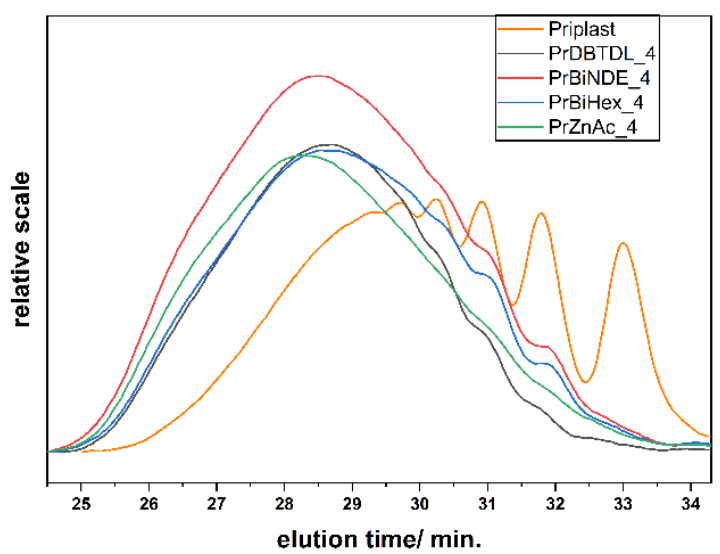

Figure 8 GPC results for (a) 2 and (b) 4 mol\% of catalysts. Closed symbols correspond to $M_{w}$ and open to $Ð\left(M_{w} / M_{n}\right)$. c), d) Chromatograms of materials obtained with use of 2 and 4 mol\%, respectively

The results of dynamic viscosity measurements are presented in Table S1 and Figure 9. For all of the macromonomers a marked increase in viscosity was observed, as compared to Priplast, indicating successful synthesis. As expected, the data largely correlated with the $\mathrm{M}_{\mathrm{w}}$ results (see Figure S13 in SI). 

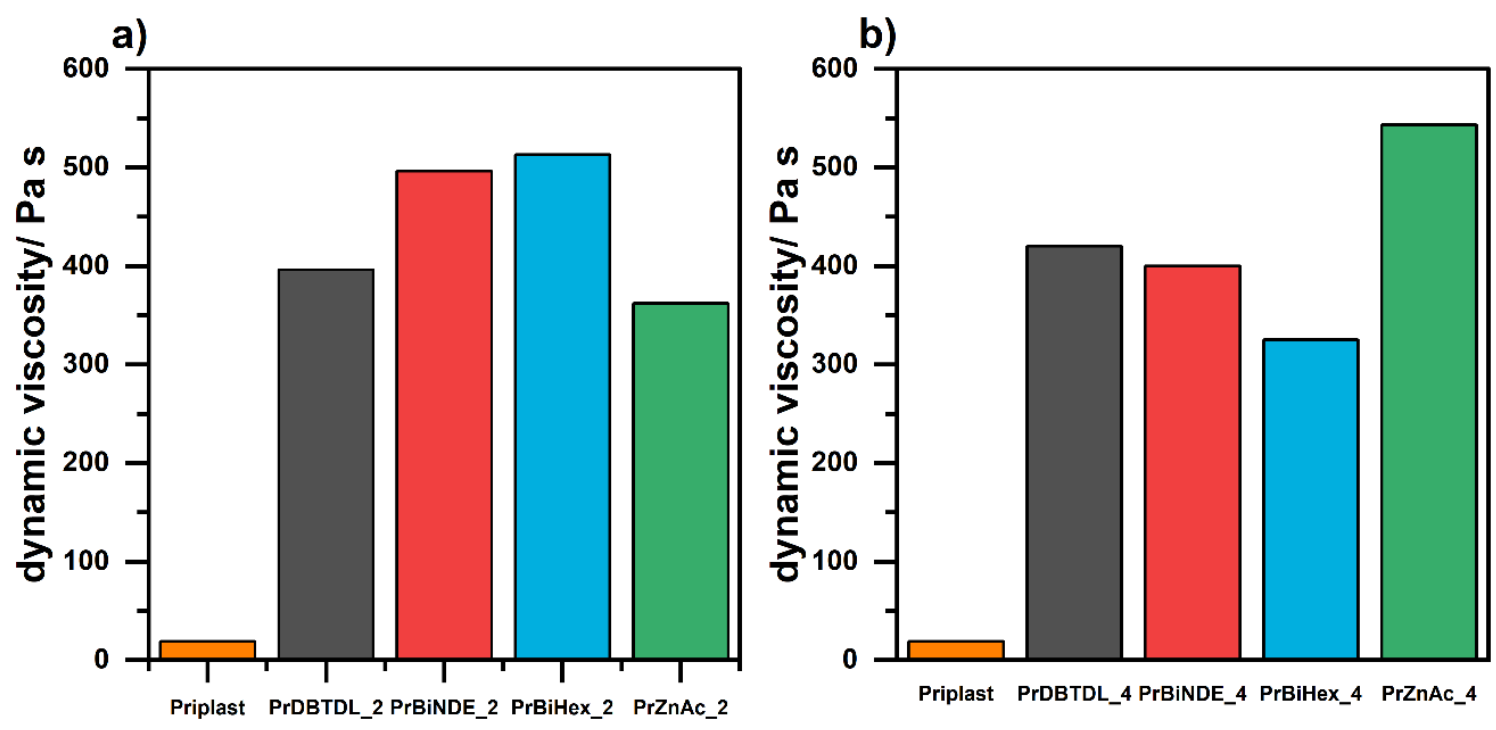

Figure 9 Dynamic viscosity of materials obtain with the use of 2 mol\% (a) and 4 mol\% (b) of catalysts.

For use in minimally invasive procedures, the rheological properties of an injectable materials play a key role. ${ }^{35}$ They must be viscous enough to be locally retained, but not so much that the material cannot be properly delivered. We conclude that the high viscosity of the obtained macromonomers should ensure that they are well retained at the desired site during the duration of the photocuring process. At the same time, with viscosities $<1000 \mathrm{~Pa}$ s, the macromonomers show injectability with the use of $16 \mathrm{G}$ needle (Figure 10 and short video in Supplementary Information). While details of a clinical delivery device (syringe, catheter, etc.) are beyond the scope of this work, we conclude that these materials should be well-suited for minimally invasive surgical procedures that use relatively large gauges of instruments, including laparoscopic and catheter procedures, such as those that may be used for cardiac repair ${ }^{36}$.

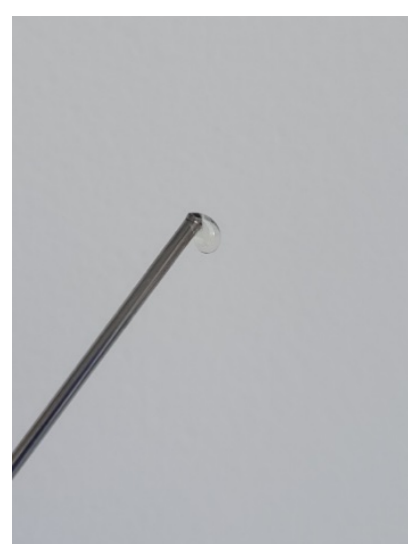




\subsection{Chemical structure of photocured elastomeric networks}

In order to confirm photocrosslinking functionality, all of the obtained macromonomers were photocured in air or under argon, following the addition of $2 \% \mathrm{w} / \mathrm{w}$ of photoinitiator (Omnirad 819). The chemical structures of cured films were confirmed by ATR FT-IR spectroscopy. Overall, the spectra of all of the cured elastomeric materials were similar. Figure 11 shows representative IR spectra of films obtained after photocuring PrBiHex_2 macromonomer in air or under argon atmosphere.

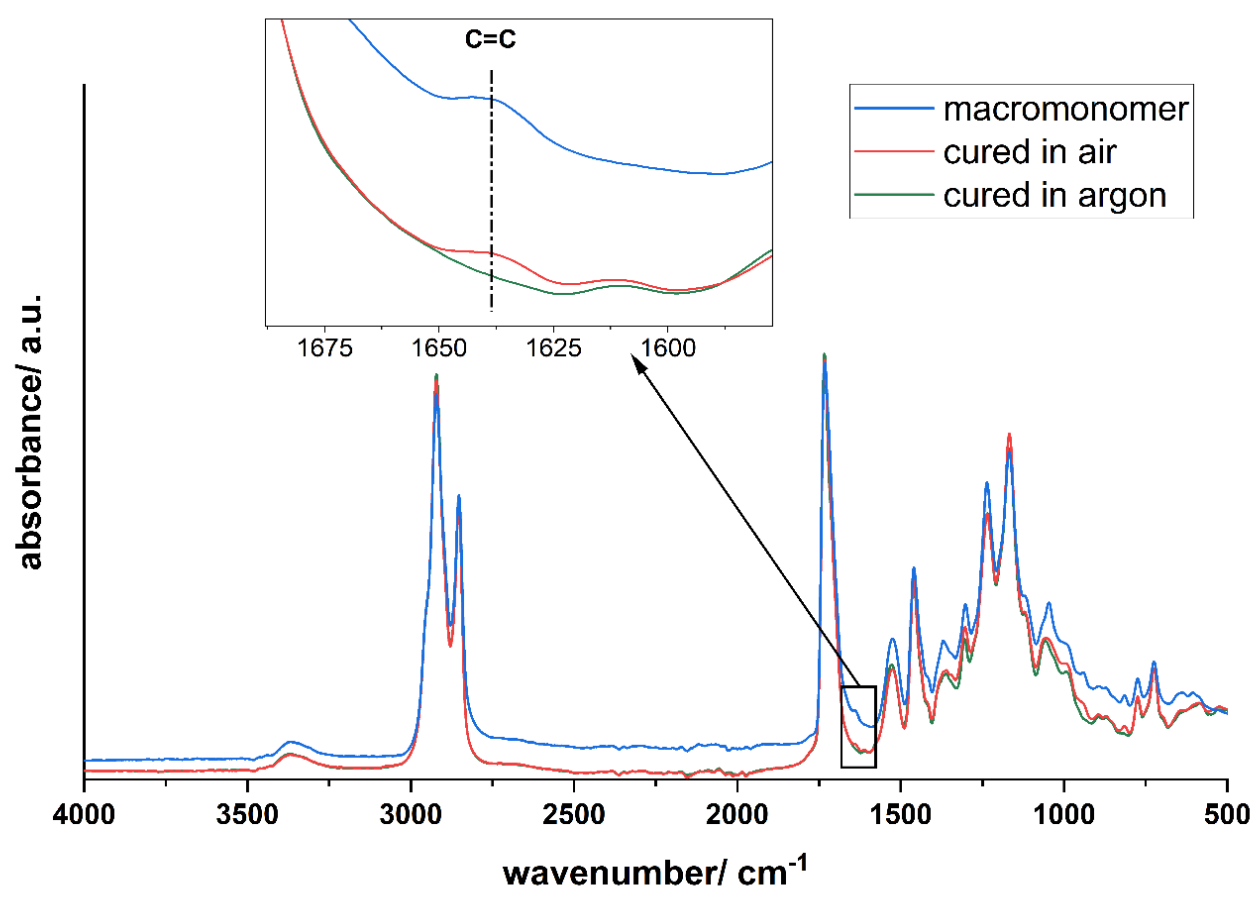

Figure 11 ATR FT-IR spectra of cured films of PrBiHex $2 \mathrm{~mol} \%$

A difference in absorbance of the band at $1643 \mathrm{~cm}^{-1}$, corresponding to stretching vibration of $\mathrm{C}=\mathrm{C}$, was observed. The carbon-carbon double bonds present in the macromonomer from the attached HEMA are converted into single carbon-carbon bonds during photopolymerization process. Thus, the higher absorbance of this band after photocuring in air indicates that oxygen inhibition had occurred. However, the gel fractions (see Table S2, in the SI) of all photocured elastomers were similar, approx. 93\% - curing atmosphere did not affect gel fraction results. 


\subsection{Mechanical analyses}

A summary of the mechanical properties of all of the obtained materials is presented in Figure 12, while representative stress-strain curves can be found in the Supplementary Information Figures S16-17. Overall, the results were broadly similar, with the differences possibly a consequence of manual sample preparation (both photocuring and cutting). It can be also observed that for the case of the non-organotin catalysts, the photocuring atmosphere (air $v s$ argon) did not have a marked effect on mechanical properties. Overall, the tensile strength was measured up to $3.5 \mathrm{MPa}$, elongation was up to $120 \%$, moduli at 2-3\% strain and 5-6\% strain were in the range of 2-6 MPa. However, in the case of the materials synthesized with both concentrations of the organotin catalyst DBTDL, the photocuring atmosphere did have an effect on the tensile strength and elongation at break: the values of these parameters obtained from materials cured under argon were approx. double those of materials cured in air. This may be explained by the oxygen inhibition having a negative effect on the photocuring process,${ }^{37}$ and in result, in final material properties. We conclude that the mechanical properties of materials obtained using non-organotin catalysts indicate their potential in medical applications. While the values are higher than those reported for living human abdominal wall tissue, as measured during laparoscopic procedures,$^{38}$ the values fall in ranges considered typical of "soft tissue" in the biomechanics literature: Young's modulus in the 0.1-10 MPa range and ultimate tensile strength and ultimate tensile strains in the range of $0.3-100 \mathrm{MPa}$ and $10-120 \%$, respectively ${ }^{39,40}$. Further, compared to other materials intended for use in soft tissue engineering, like hernia repair, reported in the literature, our materials have approx. 10-times lower modulus of elasticity values $^{41,42}$. 

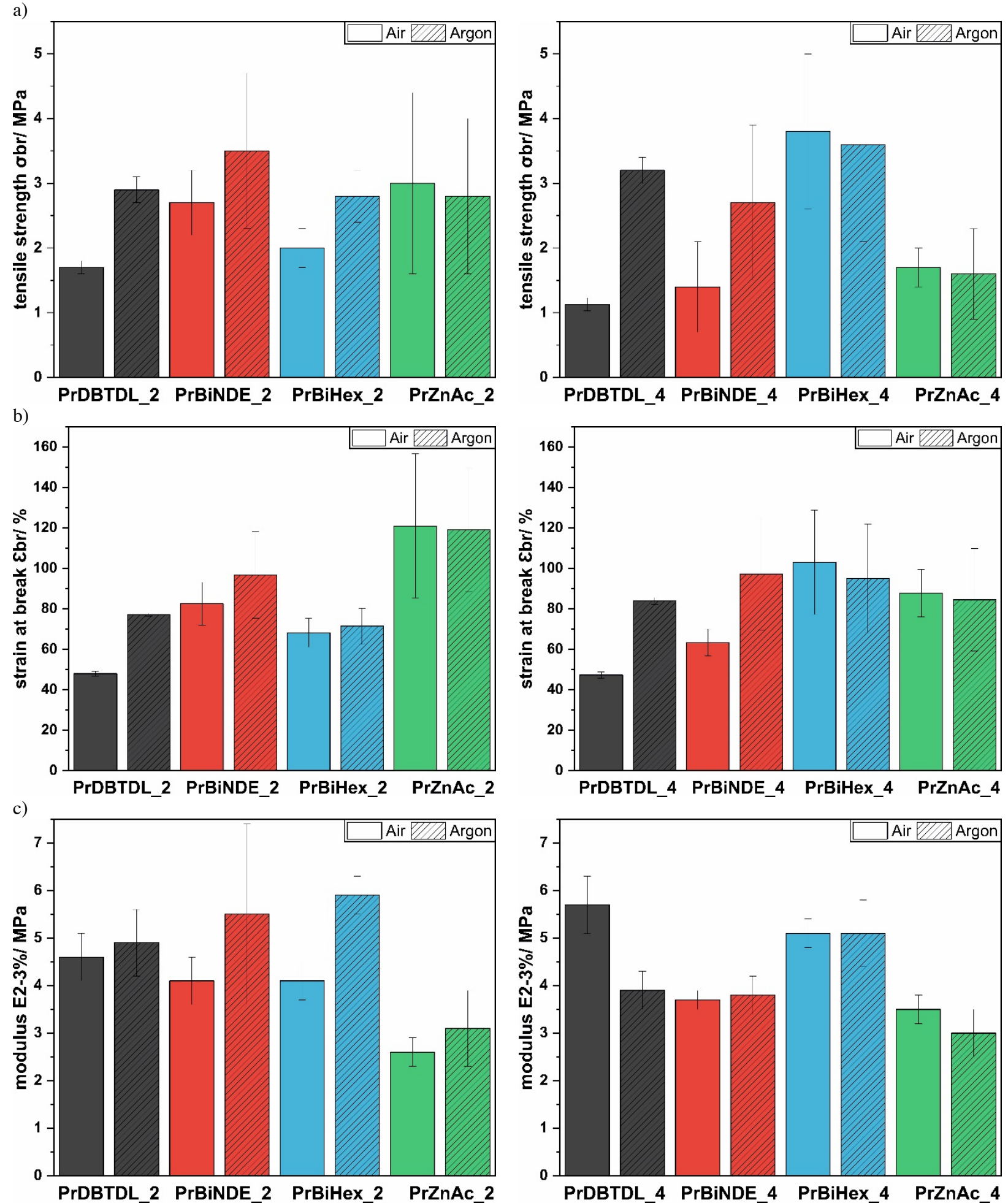
d)

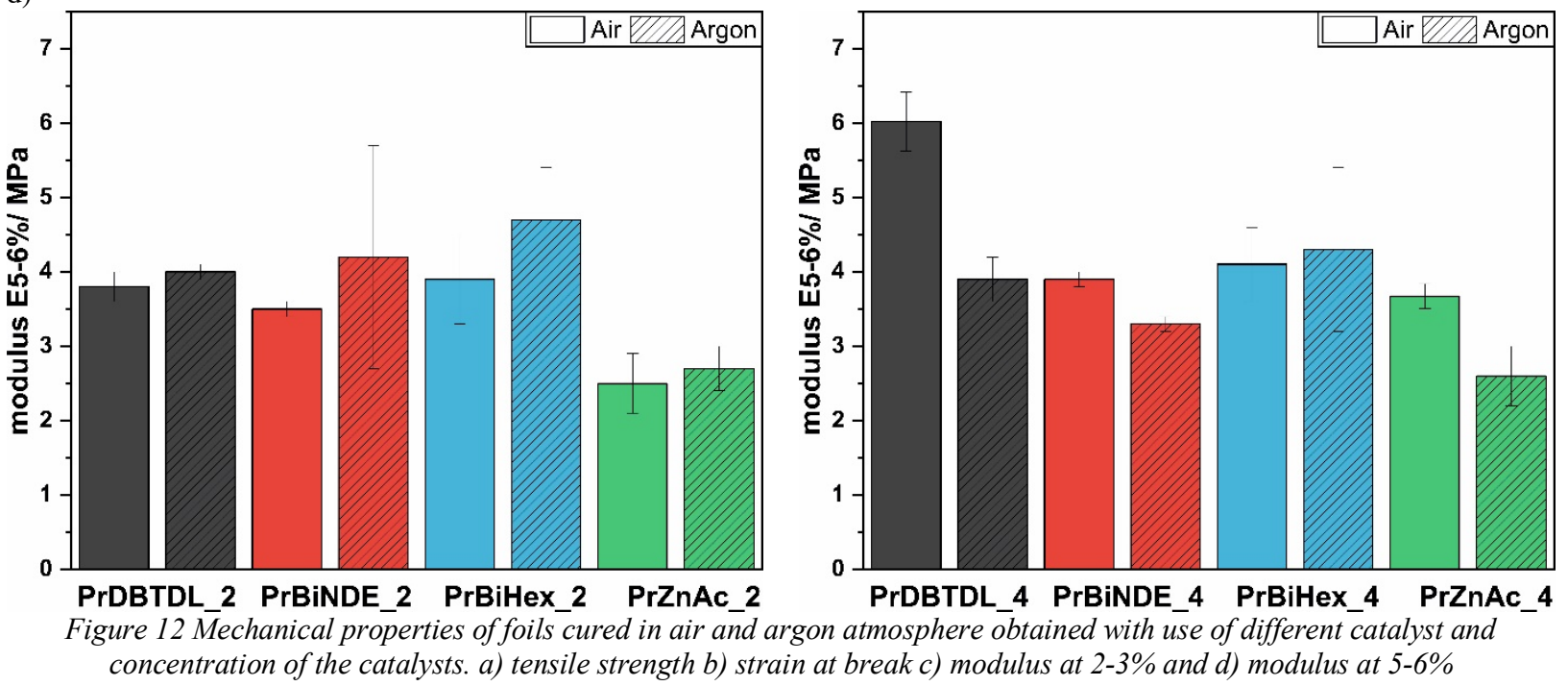

\subsection{Cell viability}

Finally, to confirm suitability for biomedical applications, we assessed cytotoxicity based on ISO 10993-5. Cell viability assay results for L929 mouse fibroblasts exposed to extracts of the tested materials for 24 hours are presented in Figure 13 (representative phase contrast photomicrographs are available in the Supplementary Information Figure S18-19). As anticipated, the use of tin-free catalysts resulted in higher cell viability for all tested conditions (catalyst concentration and atmosphere), with a trend towards higher viability in the case of materials synthesized with ZnAc catalyst. As an organotin catalyst, DBTDL is known to be highly toxic and-equally importantly - is very difficult to remove from polymers during purification. ${ }^{43,44,45}$ Based on the literature, DBTDL can be estimated to have an IC50 of approx. $3 \mu \mathrm{g} / \mathrm{mL},{ }^{43}$ which is an order of magnitude more toxic than various zinc and bismuth salts. ${ }^{46,47}$ However, the comparisons are not perfect due to differences in experimental details. We estimate that the upper bound for residual catalyst content in our samples as prepared for the cell culture tests is in the range of $100-150 \mu \mathrm{g}$. Thus, given the similar gel fractions for all samples, the differences in cytotoxicity are likely the result of toxicity of residual DBTDL (see also Figure S15). In order to assess the potential for oxygen inhibition ${ }^{48}$, we photocured materials in both inert (argon) atmosphere as well as in open air, as may be expected to occur 
during a surgical procedure. We did not observe any effect of the atmosphere present during photocuring, indicating that the effect of oxygen inhibition is relatively modest. Likewise, FTIR analysis of all of the materials confirms the complete purification of residual HEMA (Figure S14), which has a reported IC50 of approx. $1.3 \mathrm{mg} / \mathrm{mL}^{49}$. We conclude that all of the obtained materials using non-organotin catalysts can be considered well-suited for photocuring in situ without specialized oxygen-free conditions. At the same time, this study and the cell culture experiments were intended to serve as a proof-of-concept and screening; additional animal studies will be needed to address in vivo outcomes such as inflammatory response and fibrosis. However, previous data obtained for materials obtained with use of DABCO and DBTDL catalysts in a rabbit model were very encouraging ${ }^{6}$ and we anticipate that similar - or betterresults may be obtained for materials synthesized with use of $\mathrm{Zn}$ or Bi catalysts.

a)

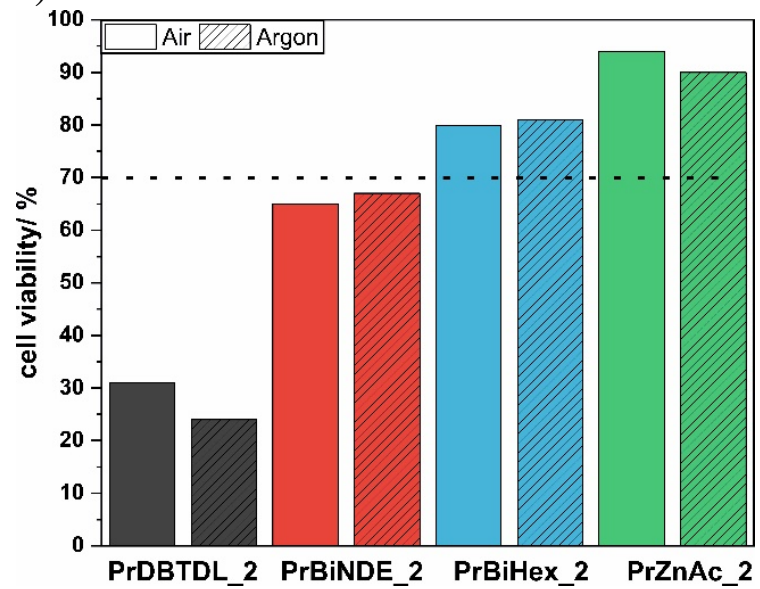

b)

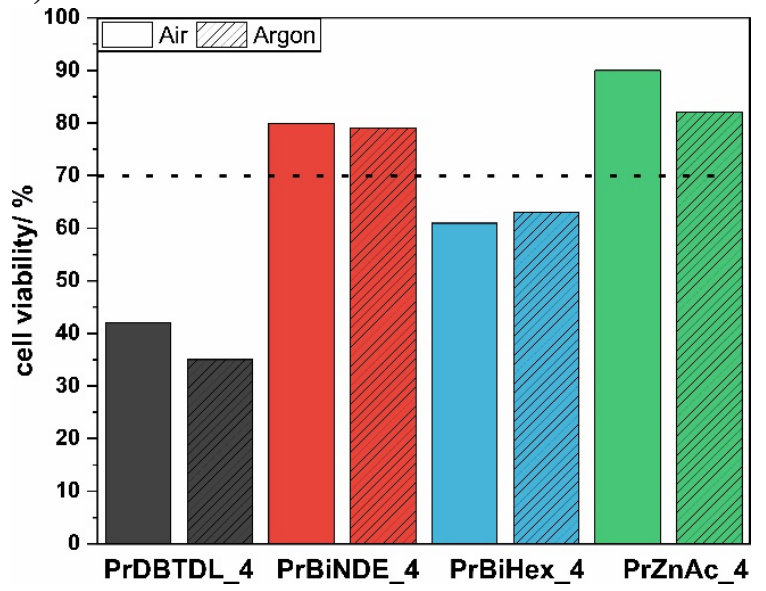

Figure 13 L929 cell viability after 24 hours of exposure to extracts of materials obtained with use of 2 (a) and 4 mol\% (b) of catalysts. The dashed line indicates the 70\% cytotoxicity threshold according to ISO10993-5.

\section{Conclusion}

We report here the synthesis of macromonomers containing ester-urethane linkage using three different non-organotin catalysts (BiNDE, BiHex, and ZnAc). FT-IR and NMR studies indicated that all of the tested catalysts resulted in the same structures for the ester-urethane 
macromonomers. Further, after photocuring, the elastomeric networks obtained from macromonomers synthesized with zinc and bismuth catalysts had suitable mechanical properties for soft tissue regenerative medicine and lower cytotoxicity, as compared to DBTDL - regardless of photocuring atmosphere. Collectively, our results indicate that it is possible to reduce the overall health and environmental safety impact of this macromonomer synthesis reaction by using less toxic catalysts and "green" solvent (ethyl acetate). This is very beneficial not only from the point of view of potential biomedical applications, but also from the safety of the process and overall life cycle of the materials. After considering of all measured parameters as well as the reaction times, we conclude that 2 mol\% of BiHex catalysts may offer the best compromise between reaction time, mechanical properties, and cell viability.

\section{Author information}

\section{Corresponding Author}

Miroslawa El Fray - Department of Polymer and Biomaterials Science,

Faculty of Chemical Technology and Engineering, West Pomeranian University of Technology in Szczecin

Al. Piastow 45, 70-311 Szczecin, POLAND https://orcid.org/0000-0002-2474-3517 *Email: mirfray@zut.edu.pl

\section{Authors}

Malwina J. Niedźwiedź, Gokhan Demirci, Nina Kantor-Malujdy, Peter Sobolewski - Department of Polymer and Biomaterials Science, Faculty of Chemical Technology and Engineering, West Pomeranian University of Technology in Szczecin, Al. Piastow 45, 70-311 Szczecin, POLAND

\section{Acknowledgements}

This work has been supported by research project OPUS17 from the Polish National Science Center (Narodowe Centrum Nauki) „Hybrid and elastomeric polymer networks: synthesis, structure and properties", UMO-2019/33/B/ST5/01445. The authors thank Karol Fijałkowski, PhD (Faculty of Biotechnology and Animal Husbandry, ZUT) for access to the multi-functional plate reader.

\section{Conflict of interests}

M. El Fray is co-inventor of patents that are licensed to PolTiss Sp. z o.o. P. Sobolewski has performed paid consulting for PolTiss Sp. $\mathrm{z}$ o.o. which is commercializing photocrosslinkable biomaterials.

\section{References}


(1) Bingmer, K.; Ofshteyn, A.; Stein, S. L.; Marks, J. M.; Steinhagen, E. Decline of Open Surgical Experience for General Surgery Residents. Surg. Endosc. 2020, 34 (2), 967972. https://doi.org/10.1007/s00464-019-06881-0.

(2) Raucci, M. G.; D’Amora, U.; Ronca, A.; Ambrosio, L. Injectable Functional Biomaterials for Minimally Invasive Surgery. Adv. Healthc. Mater. 2020, 9 (13), 2000349. https://doi.org/10.1002/adhm.202000349.

(3) Zhou, H.; Liang, C.; Wei, Z.; Bai, Y.; Bhaduri, S. B.; Webster, T. J.; Bian, L.; Yang, L. Injectable Biomaterials for Translational Medicine. Mater. Today 2019, 28 (September), 81-97. https://doi.org/10.1016/j.mattod.2019.04.020.

(4) Dimatteo, R.; Darling, N. J.; Segura, T. In Situ Forming Injectable Hydrogels for Drug Delivery and Wound Repair. Adv. Drug Deliv. Rev. 2018, 127, 167-184. https://doi.org/10.1016/j.addr.2018.03.007.

(5) Chen, Q. Z.; Harding, S. E.; Ali, N. N.; Lyon, A. R.; Boccaccini, A. R. Biomaterials in Cardiac Tissue Engineering: Ten Years of Research Survey. Mater. Sci. Eng. R Reports 2008, 59 (1-6), 1-37. https://doi.org/10.1016/j.mser.2007.08.001.

(6) Skrobot, J.; Zair, L.; Ostrowski, M.; El Fray, M. New Injectable Elastomeric Biomaterials for Hernia Repair and Their Biocompatibility. Biomaterials 2016, 75 , 182-192. https://doi.org/10.1016/j.biomaterials.2015.10.037.

(7) El Fray, M.; Skrobot, J.; Bolikal, D.; Kohn, J. Synthesis and Characterization of Telechelic Macromers Containing Fatty Acid Derivatives. React. Funct. Polym. 2012, 72 (11), 781-790. https://doi.org/10.1016/j.reactfunctpolym.2012.07.010.

(8) Akindoyo, J. O.; Beg, M. D. H.; Ghazali, S.; Islam, M. R.; Jeyaratnam, N.; Yuvaraj, A. R. Polyurethane Types, Synthesis and Applications - a Review. RSC Adv. 2016, 6 (115), 114453-114482. https://doi.org/10.1039/C6RA14525F.

(9) Skrobot, J.; Ignaczak, W.; El Fray, M. Hydrolytic and Enzymatic Degradation of Fl Exible Polymer Networks Comprising Fatty Acid Derivatives. Polym. Degrad. Stab. 2015, 120, 368-376. https://doi.org/10.1016/j.polymdegradstab.2015.07.022.

(10) Gao, Y.; Dong, H.; Liu, L.; Yu, Y.; Tang, Z.; Bai, C.; Schmidt, T.; Feng, Y.; Chen, H. Tin-Containing Crystalline Copolymers as Latent Catalysts for Polyurethanes. $A C S$ Appl. Polym. Mater. 2020, 2 (11), 4531-4540. https://doi.org/10.1021/acsapm.0c00627.

(11) Arnould, P.; Bosco, L.; Sanz, F.; Simon, F. N.; Fouquay, S.; Michaud, G.; Raynaud, J.; Monteil, V. Identifying Competitive Tin- or Metal-Free Catalyst Combinations to Tailor Polyurethane Prepolymer and Network Properties. Polym. Chem. 2020, 11 (36), 5725-5734. https://doi.org/10.1039/D0PY00864H.

(12) Tanzi, M. C.; Verderio, P.; Lampugnani, M. G.; Resnati, M.; Dejana, E.; Sturani, E. Cytotoxicity of Some Catalysts Commonly Used in the Synthesis of Copolymers for Biomedical Use. J. Mater. Sci. Mater. Med. 1994, 5 (6-7), 393-396.

https://doi.org/10.1007/BF00058971. 
(13) Dubalska, K.; Rutkowska, M.; Bajger-Nowak, G.; Konieczka, P.; Namieśnik, J. Organotin Compounds: Environmental Fate and Analytics. Crit. Rev. Anal. Chem. 2013, 43 (1), 35-54. https://doi.org/10.1080/10408347.2012.743846.

(14) Qiao, X.; Li, Y.; Mai, J.; Ji, X.; Li, Q. Effect of Dibutyltin Dilaurate on Triglyceride Metabolism through the Inhibition of the MTOR Pathway in Human HL7702 Liver Cells. Molecules 2018, 23 (7), 1-15. https://doi.org/10.3390/molecules23071654.

(15) Sardon, H.; Pascual, A.; Mecerreyes, D.; Taton, D.; Cramail, H.; Hedrick, J. L. Synthesis of Polyurethanes Using Organocatalysis: A Perspective. Macromolecules 2015, 48 (10), 3153-3165. https://doi.org/10.1021/acs.macromol.5b00384.

(16) Kricheldorf, H. R. Syntheses of Biodegradable and Biocompatible Polymers by Means of Bismuth Catalysts. Chem. Rev. 2009, 109 (11), 5579-5594. https://doi.org/10.1021/cr900029e.

(17) Schellekens, Y.; Van Trimpont, B.; Goelen, P.-J.; Binnemans, K.; Smet, M.; Persoons, M.-A.; De Vos, D. Tin-Free Catalysts for the Production of Aliphatic Thermoplastic Polyurethanes. Green Chem. 2014, 16 (9), 4401-4407. https://doi.org/10.1039/C4GC00873A.

(18) Guhl, D. Alternatives to DBTL Catalysts in Polyurethanes - a Comparative Study. Polyurethanes High Perform. Coatings, Eur. Coatings Conf. 5 2008, No. February 2008, 119-137. https://doi.org/10.13140/2.1.2416.3209.

(19) Baek, K. J.; Lee, H. M.; Ju, S. H.; Kim, Y.-R.; Choe, A.; Ko, H.; Kim, G. Y.; Kim, M. P.; Kim, J. C.; Cheong, I. W. Catalytic Effects of Zirconium on Scratch-Healing and Mechanical Properties of Urethane-Acrylate Automotive Clearcoat. Prog. Org. Coatings 2020, 148 (May), 105813. https://doi.org/10.1016/j.porgcoat.2020.105813.

(20) Blank, W. J.; He, Z. A.; Hessell, E. T. Catalysis of the Isocyanate-Hydroxyl Reaction by Non-Tin Catalysts. Prog. Org. Coatings 1999, 35 (1-4), 19-29. https://doi.org/10.1016/S0300-9440(99)00006-5.

(21) Stamenković, J.; Caki, S.; Konstantinovi, S.; Stoilkovi, S. Catalysis of the IsocyanateHydroxyl Reaction by Non-Tin Catalysis in Waterborne Two Component Polyurethane Coatings. Work. Living Environ. Prot. 2004, 2 (4), 243-250.

(22) Aggen, D. H.; Arnold, J. N.; Hayes, P. D.; Smoter, N.; Mohan, R. S. Bismuth Compounds in Organic Synthesis. Bismuth Nitrate Catalyzed Chemoselective Synthesis of Acylals from Aromatic Aldehydes. Tetrahedron 2004, 60 (16), 36753679. https://doi.org/10.1016/j.tet.2004.02.046.

(23) El Ghaoui, H.; Raihane, M.; Rhouta, B.; Bitinis, N.; Carlmark, A.; Arroyo, M.; Verdejo, R.; Lopez-Manchado, M. A.; Lahcini, M. Bismuth Complex Catalysts for the in Situ Preparation of Polycaprolactone/Silicate Bionanocomposites. Polym. Int. 2014, 63 (4), 709-717. https://doi.org/10.1002/pi.4576.

(24) Blank, W. J. New Developments in Catalysis. Macromol. Symp. 2002, 187, 261-270. https://doi.org/10.1002/1521-3900(200209)187:1<261::AID-MASY261>3.0.CO;2-P. 
(25) Bonné, C.; Pahwa, A.; Picard, C.; Visseaux, M. Bismuth Tris-Silylamide: A New NonToxic Metal Catalyst for the Ring Opening (Co-)Polymerization of Cyclic Esters under Smooth Conditions. Inorganica Chim. Acta 2017, 455, 521-527. https://doi.org/10.1016/j.ica.2016.06.027.

(26) Byrne, F. P.; Jin, S.; Paggiola, G.; Petchey, T. H. M.; Clark, J. H.; Farmer, T. J.; Hunt, A. J.; Robert McElroy, C.; Sherwood, J. Tools and Techniques for Solvent Selection: Green Solvent Selection Guides. Sustain. Chem. Process. 2016, 4 (1), 7. https://doi.org/10.1186/s40508-016-0051-z.

(27) Hernández-Gascón, B.; Peña, E.; Melero, H.; Pascual, G.; Doblaré, M.; Ginebra, M. P.; Bellón, J. M.; Calvo, B. Mechanical Behaviour of Synthetic Surgical Meshes: Finite Element Simulation of the Herniated Abdominal Wall. Acta Biomater. 2011, 7 (11), 3905-3913. https://doi.org/10.1016/j.actbio.2011.06.033.

(28) ISO. Biological Evaluation of Medical Devices - Part 5: Tests for in Vitro Cytotoxicity; Geneva, Switzerland, 2009.

(29) Łopusiewicz, Ł.; Drozłowska, E.; Trocer, P.; Kostek, M.; Śliwiński, M.; Henriques, M. H. F.; Bartkowiak, A.; Sobolewski, P. Whey Protein Concentrate/Isolate Biofunctional Films Modified with Melanin from Watermelon (Citrullus Lanatus) Seeds. Materials (Basel). 2020, 13 (17), 3876. https://doi.org/10.3390/ma13173876.

(30) Sokolowska, M.; El Fray, M. “ Green ” Poly ( Butylene Succinate- Co -Dilinoleic Succinate ) Copolymers Synthesized Using Candida Antarctica Lipase B. Proc. 2021 2021, 69 (33), 1-7. https://doi.org/10.3390/CGPM2020-07221.

(31) Riss, T. L.; Moravec, R. A.; Niles, A. L.; Benink, H. A.; Worzella, T. J.; Minor, L.; Storts, D.; Reid, Y. Cell Viability Assays. Assay Guidance Manual [Internet]. 2013, pp $1-27$.

(32) Sukhorukov, A. Y.; Sukhanova, A. A.; Zlotin, S. G. Stereoselective Reactions of Nitro Compounds in the Synthesis of Natural Compound Analogs and Active Pharmaceutical Ingredients. Tetrahedron 2016, 72 (41), 6191-6281. https://doi.org/10.1016/j.tet.2016.07.067.

(33) Danielmeier, K.; Schmalstieg, L.; Laas, H.-J.; Mertens, H.; Jahn, R. Light-Fast Polyisocyanates Having Good Solubility in Non-Polar Solvents.Pdf. CA 2311045.

(34) Lapprand, A.; Boisson, F.; Delolme, F.; Méchin, F.; Pascault, J.-P. Reactivity of Isocyanates with Urethanes: Conditions for Allophanate Formation. Polym. Degrad. Stab. 2005, 90 (2), 363-373. https://doi.org/10.1016/j.polymdegradstab.2005.01.045.

(35) McLemore, R. Rheological Properties of Injectable Biomaterials. In Injectable Biomaterials; Elsevier, 2011; pp 46-60. https://doi.org/10.1533/9780857091376.1.46.

(36) Hinderer, S.; Brauchle, E.; Schenke-Layland, K. Generation and Assessment of Functional Biomaterial Scaffolds for Applications in Cardiovascular Tissue Engineering and Regenerative Medicine. Adv. Healthc. Mater. 2015, 4 (16), 23262341. https://doi.org/10.1002/adhm.201400762. 
(37) Andrzejewska, E. Photopolymerization Kinetics of Multifunctional Monomers. Prog. Polym. Sci. 2001, 26 (4), 605-665. https://doi.org/Doi 10.1016/S0079-6700(01)000041.

(38) Song, C.; Alijani, A.; Frank, T.; Hanna, G.; Cuschieri, A. Elasticity of the Living Abdominal Wall in Laparoscopic Surgery. J. Biomech. 2006, 39 (3), 587-591. https://doi.org/10.1016/j.jbiomech.2004.12.019.

(39) Akhtar, R.; Sherratt, M. J.; Cruickshank, J. K.; Derby, B. Characterizing the Elastic Properties of Tissues. Mater. Today 2011, 14 (3), 96-105. https://doi.org/10.1016/S1369-7021(11)70059-1.

(40) HOLZAPFEL, G. A. Biomechanics of Soft Tissue. In Handbook of Materials Behavior Models; Elsevier, 2001; pp 1057-1071. https://doi.org/10.1016/B978-0124433410/50107-1.

(41) Floden, E. W.; Malak, S. F. F.; Basil-Jones, M. M.; Negron, L.; Fisher, J. N.; Lun, S.; Dempsey, S. G.; Haverkamp, R. G.; Ward, B. R.; May, B. C. H. Biophysical Characterization of Ovine Forestomach Extracellular Matrix Biomaterials. J. Biomed. Mater. Res. Part B Appl. Biomater. 2011, 96B (1), 67-75. https://doi.org/10.1002/jbm.b.31740.

(42) Raghavan, D.; Kropp, B. P.; Lin, H.-K.; Zhang, Y.; Cowan, R.; Madihally, S. V. Physical Characteristics of Small Intestinal Submucosa Scaffolds Are LocationDependent. J. Biomed. Mater. Res. Part A 2005, 73 A (1), 90-96. https://doi.org/10.1002/jbm.a.30268.

(43) Tanzi, M. C.; Verderio, P.; Lampugnani, M. G.; Resnati, M.; Dejana, E.; Sturani, E. Cytotoxicity of Some Catalysts Commonly Used in the Synthesis of Copolymers for Biomedical Use. J. Mater. Sci. Mater. Med. 1994, 5 (6-7), 393-396. https://doi.org/10.1007/BF00058971.

(44) Sardon, H.; Pascual, A.; Mecerreyes, D.; Taton, D.; Cramail, H.; Hedrick, J. L. Synthesis of Polyurethanes Using Organocatalysis: A Perspective. Macromolecules 2015, 48 (10), 3153-3165. https://doi.org/10.1021/acs.macromol.5b00384.

(45) Coady, D. J.; Horn, H. W.; Jones, G. O.; Sardon, H.; Engler, A. C.; Waymouth, R. M.; Rice, J. E.; Yang, Y. Y.; Hedrick, J. L. Polymerizing Base Sensitive Cyclic Carbonates Using Acid Catalysis. ACS Macro Lett. 2013, 2 (4), 306-312. https://doi.org/10.1021/mz3006523.

(46) Pavlica, S.; Gaunitz, F.; Gebhardt, R. Comparative in Vitro Toxicity of Seven ZincSalts towards Neuronal PC12 Cells. Toxicol. Vitr. 2009, 23 (4), 653-659. https://doi.org/10.1016/j.tiv.2009.03.003.

(47) Rodilla, V.; Miles, A. T.; Jenner, W.; Hawksworth, G. M. Exposure of Cultured Human Proximal Tubular Cells to Cadmium, Mercury, Zinc and Bismuth: Toxicity and Metallothionein Induction. Chem. Biol. Interact. 1998, 115 (1), 71-83. https://doi.org/10.1016/S0009-2797(98)00059-3. 
(48) Ligon, S. C.; Husár, B.; Wutzel, H.; Holman, R.; Liska, R. Strategies to Reduce Oxygen Inhibition in Photoinduced Polymerization. Chem. Rev. 2014, 114 (1), $557-$ 589. https://doi.org/10.1021/cr3005197.

(49) Yoshii, E. Cytotoxic Effects of Acrylates and Methacrylates: Relationships of Monomer Structures and Cytotoxicity. J. Biomed. Mater. Res. 1997, 37 (4), 517-524. https://doi.org/10.1002/(SICI) 1097-4636(19971215)37:4<517::AID-JBM10>3.0.CO;25 . 